WALDEN

UNIVERSITY

A higher degree. A higher purpose.

Walden University ScholarWorks

2018

\title{
Strategies for Implementing Innovation in Small and Medium-Sized Enterprises
}

Monther I. S. Haddad

Walden University

Follow this and additional works at: https://scholarworks.waldenu.edu/dissertations

Part of the Business Commons

This Dissertation is brought to you for free and open access by the Walden Dissertations and Doctoral Studies Collection at ScholarWorks. It has been accepted for inclusion in Walden Dissertations and Doctoral Studies by an authorized administrator of ScholarWorks. For more information, please contact ScholarWorks@waldenu.edu. 


\title{
Walden University
}

\author{
College of Management and Technology
}

This is to certify that the doctoral study by

Monther I.S. Haddad

has been found to be complete and satisfactory in all respects, and that any and all revisions required by the review committee have been made.

\section{Review Committee}

Dr. Irene Williams, Committee Chairperson, Doctor of Business Administration Faculty

Dr. Mohamad Hammoud, Committee Member, Doctor of Business Administration Faculty

Dr. Rocky Dwyer, University Reviewer, Doctor of Business Administration Faculty

Chief Academic Officer

Eric Riedel, Ph.D.

Walden University

2018 


\begin{abstract}
Strategies for Implementing Innovation in Small and Medium-Sized Enterprises by

Monther I. S. Haddad

MS, Jordan University of Science \& Technology, 1999

BS, Jordan University of Science \& Technology, 1996

\author{
Doctoral Study Submitted in Partial Fulfillment \\ of the Requirements for the Degree of \\ Doctor of Business Administration
}

Walden University

October 2018 


\begin{abstract}
Inefficient processes for innovation implementation can prevent owners of small and medium-sized enterprises from realizing goals and growth potential. The purpose of this multiple case study was to explore strategies that managers of small and medium-sized enterprises use to implement innovation in their organizations to improve performance. The population for this study consisted of 5 managers from 4 small and medium-sized enterprises operating in Dubai. The resource-based view theory was the conceptual framework of this study. Data were collected through face-to-face interviews and review of companies' documents. Data were analyzed using Yin's 5-step process. After transcribing the interviews and coding the resulting transcripts, the key themes that emerged included: the role of the top management in cultivating an innovative culture, the identification of ideas as the starting points for innovation, and the recognition of customers as resources for the company. Managers of small and medium-sized enterprises might benefit from the results of this study by implementing the recommendations and strategies to improve performance. Implications for social change include the potential to create employment opportunities and improve the living conditions of the employees in Dubai through economic growth.
\end{abstract}


Strategies for Implementing Innovation in Small and Medium-Sized Enterprises by

Monther I. S. Haddad

MS, Jordan University of Science \& Technology, 1999

BS, Jordan University of Science \& Technology, 1996

Doctoral Study Submitted in Partial Fulfillment

of the Requirements for the Degree of

Doctor of Business Administration

Walden University

October 2018 


\section{Dedication}

I dedicate this doctoral study to my lovely wife, Abeer, for her unwavering patience, support, and encouragement. I feel blessed to have her by my side each and every day. 


\section{Acknowledgments}

I would like to express my sincere gratitude to my committee chair, Dr. Irene Williams for her encouragement, guidance, and supportive feedback. I learned a lot from her teaching style and academic experience. I extend my gratitude to my second committee member, Dr. Mohamad S. Hammoud, for his insights and advice. Also, I would like to thank my URR, Dr. Rocky Dwyer for his detailed reviews and constructive feedback. I would like to thank Dr. Yvonne Doll and Dr. Brenda Jack for their support. 
Table of Contents

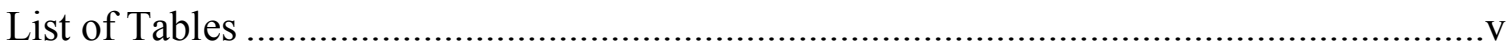

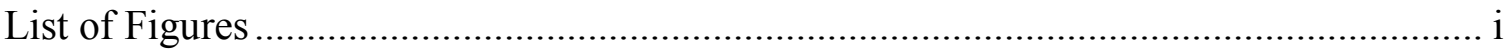

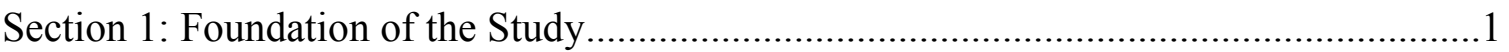

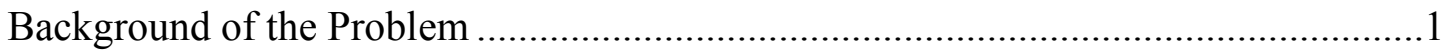

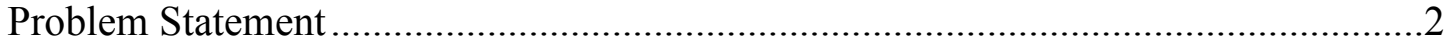

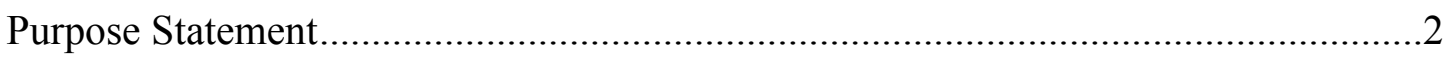

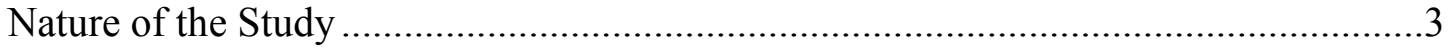

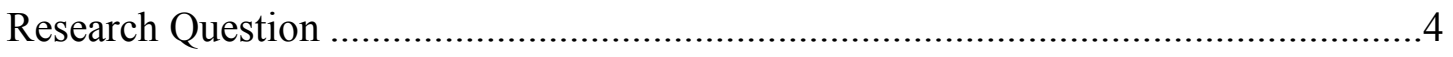

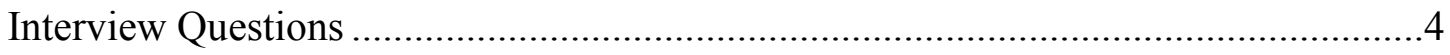

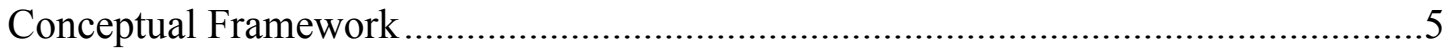

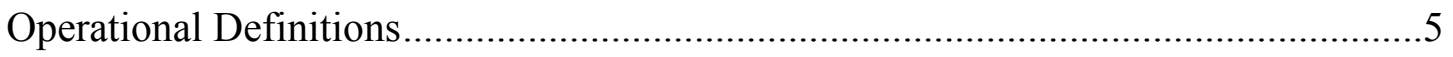

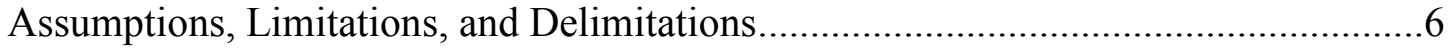

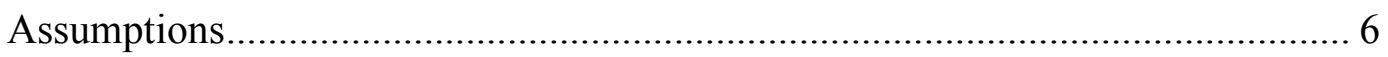

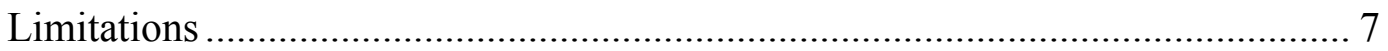

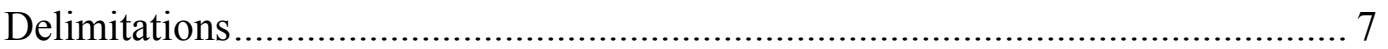

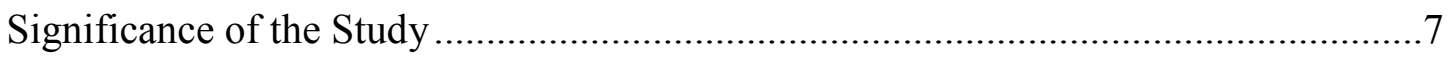

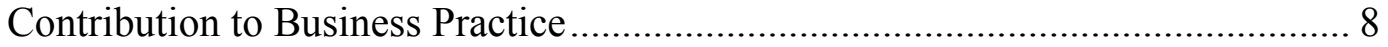

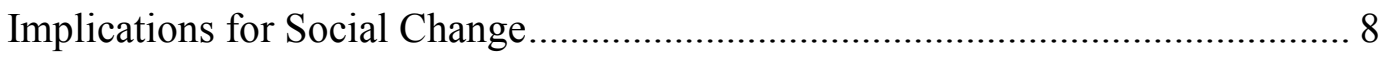

A Review of the Professional and Academic Literature .........................................

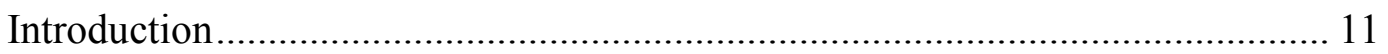

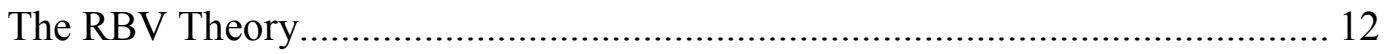


Definition of Resources in the Context of the RBV Theory.............................. 15

Using the RBV Theory to Study Innovation in SMEs..................................... 18

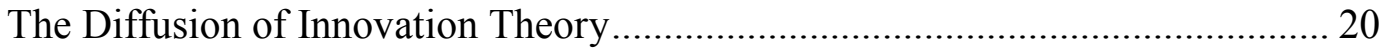

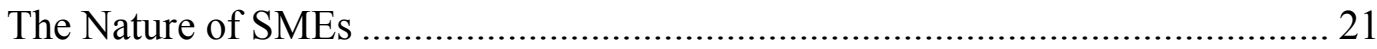

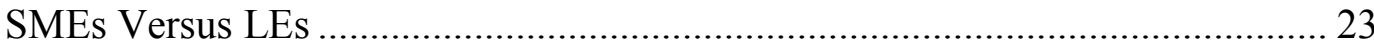

The Role of SME in Economic Development .................................................. 25

The Status of SMEs in Dubai........................................................................ 27

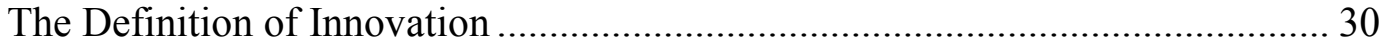

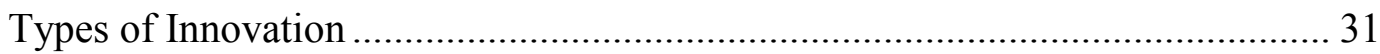

The Role of Innovation in Improving the Performance of SMEs....................... 35

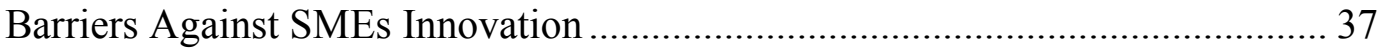

The Role of SME Managers in Innovation and Culture Change ......................... 38

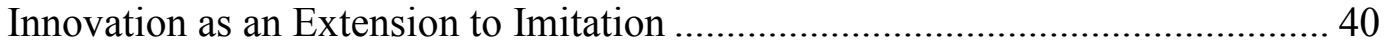

Cooperation Networks to Overcome Resource Limitations in SMEs ................. 41

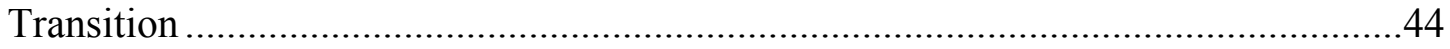

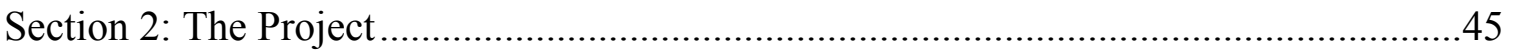

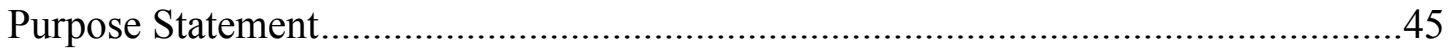

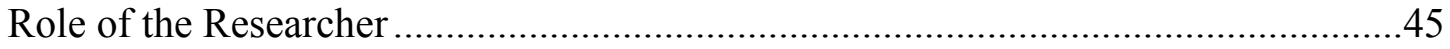

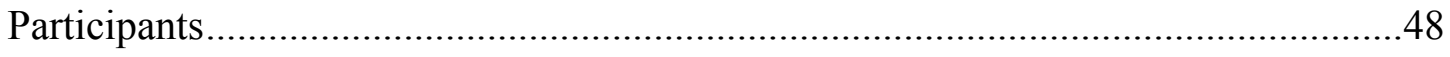

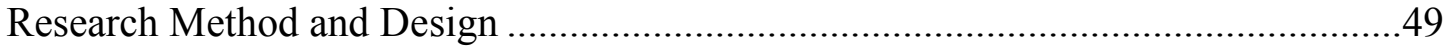

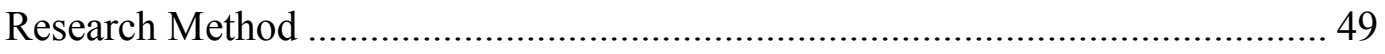

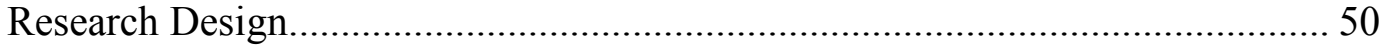




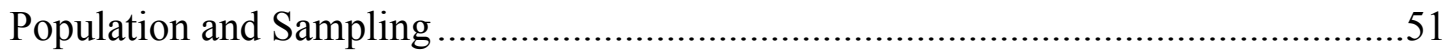

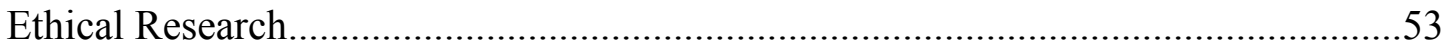

Data Collection Instruments …………………………….................................54

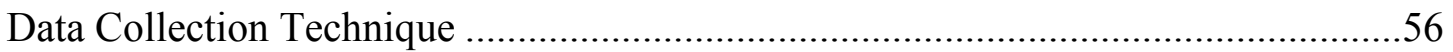

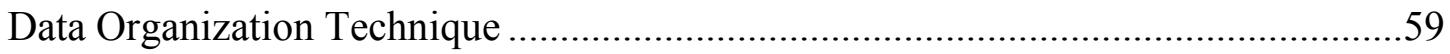

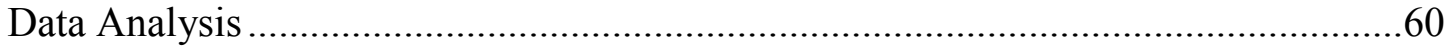

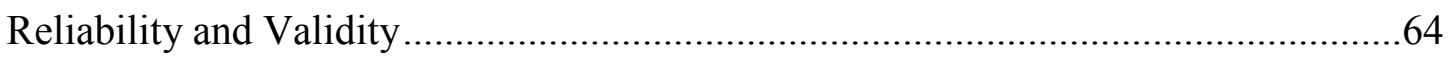

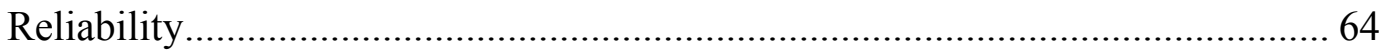

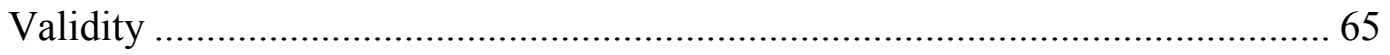

Transition and Summary ...............................................................................67

Section 3: Application to Professional Practice and Implications for Change ...................68

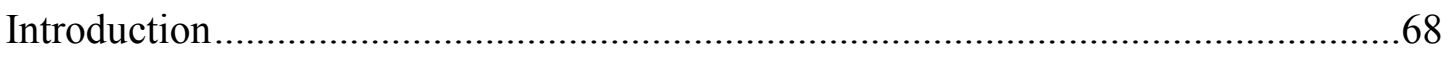

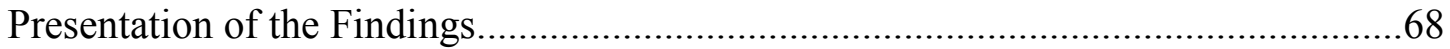

Theme 1: The Role of Innovation in Competition and Survival .......................... 70

Theme 2: Ideas are the Starting Points for Innovation ......................................... 73

Theme 3: The Role of the Top Management in Cultivating an Innovative

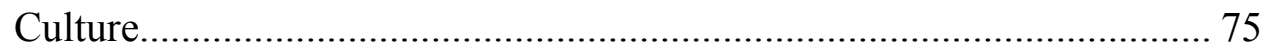

Theme 4: Idea Testing, Idea Evaluation, and Seeking Honest Feedback ............. 79

Theme 5: The Customer as a Resource for the Company .................................... 82

Applications to Professional Practice .....................................................................8

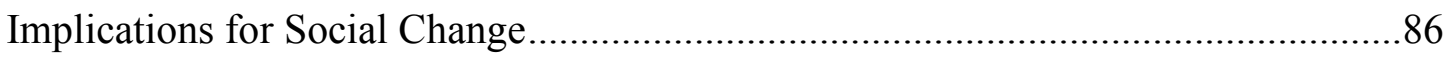

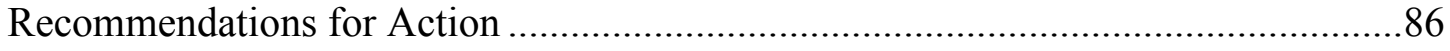


Encourage the Employees to Generate New Ideas ............................................ 87

Create an Innovative Corporate Culture .................................................... 87

Formulate and Communicate a Clear Vision and Clear Goals .......................... 87

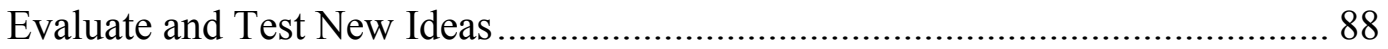

Seek Honest Feedback and Accepting Criticism ............................................ 88

Seek and Maintain a Constant Communication with the Customers................... 88

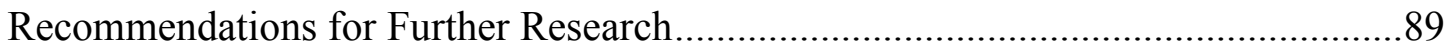

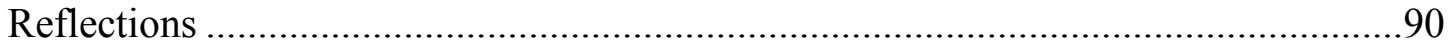

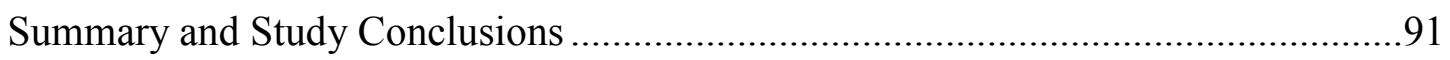

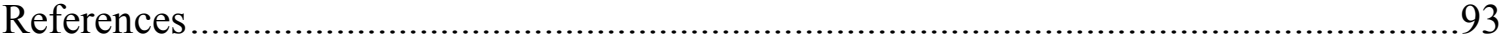

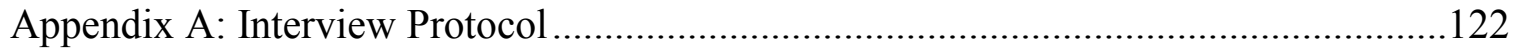




\section{List of Tables}

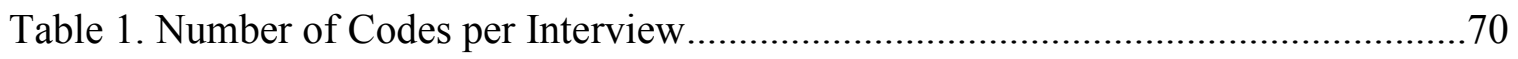

Table 2. Frequency of Main Theme One …......................................................... 71

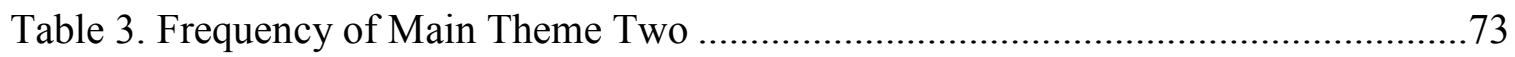

Table 4. Frequency of Main Theme Three …............................................................ 76

Table 5. Frequency of Sub-themes under Main Theme Three .....................................76

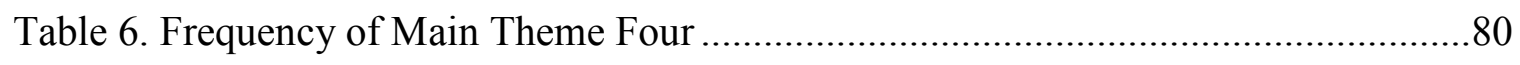

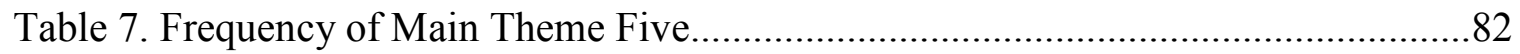




\section{List of Figures}

Figure 1. The structure of the literature review ............................................................ 
Section 1: Foundation of the Study

Small and medium enterprises (SMEs) are the engine of economic development as they are the largest employer in the world and a major contributor to a country's gross domestic product (Katua, 2014). Despite the availability of a wealth of studies about SME innovation in developed countries, there is a lack of information about the innovation of SMEs in developing countries (Xie, Zeng, Peng, \& Tam, 2013). In one of the studies in Dubai, Al-Ansari, Pervan, and Xu (2013) found that innovation had a positive impact on SME performance. However, the authors did not study how SME managers can use innovation to improve their organizations' performance. The main purpose of this study was to explore strategies that some SME managers use to implement innovation in their organizations to meet performance goals.

\section{Background of the Problem}

Innovation has the potential to improve performance. However, the inefficient implementation of innovation does not generate the expected results, especially in SMEs (Norek, 2014; Xie et al., 2013). SMEs represent a significant part of local and global economies by constituting around $90 \%$ of the total active firms worldwide (Shrirame \& Soni, 2015). Despite the role that SMEs play in the local and global economy, few studies addressed the issue of innovation implementation in SMEs especially in developing countries (Xie et al., 2013). The lack of studies about the implementation of innovation in SMEs operating in developing countries calls for more research to address this gap. 
Al-Ansari et al. (2013) found a positive impact of innovation on performance in Dubai SMEs, yet their research did not specify how SME managers could implement innovation. The main objective of this study was to explore strategies that some SME managers use to implement innovation in their organizations to meet performance goals. This study included an exploration of SME managers' views to identify recommendations for improving SME performance.

\section{Problem Statement}

While innovation can improve the performance of SMEs (Hajar, 2015), many times the innovation activities of SMEs are inefficient (Norek, 2014). Although SMEs in Dubai constitute $95 \%$ of the enterprise population, only $13 \%$ of SMEs implement innovation (Dubai SME, 2014). The general business problem is that the lack of innovation impacts SME performance and competitiveness. The specific business problem is that some SME managers lack strategies to implement innovation in their organizations to meet performance goals.

\section{Purpose Statement}

The purpose of this qualitative multiple case study was to explore strategies that some SME managers use to implement innovation in their organizations to meet performance goals. The target population was five managers from four SMEs in Dubai, who have successfully implemented innovation in their organizations to meet performance goals. The implication for positive social change includes the potential to create employment opportunities and reduce poverty in developing countries through economic growth. 


\section{Nature of the Study}

A qualitative methodology was the basis for this study to explore strategies that some SME managers used to implement innovation in their organizations to meet performance goals. Researchers use the qualitative methodology to focus on the interpretation of a phenomenon in its natural setting by trying to understand the phenomenon from the point of view of the people involved (Denzin \& Lincoln, 2013). Researchers can use quantitative methods at later stages of the study to quantify specific variables in a numerical statistical form or to test a certain hypothesis (McCusker \& Gunaydin, 2015). Researchers use mixed methods when a single methodology does not provide a sufficient understanding of the topic under study (Lee, 2014). A mixedmethod was not suitable for this study because the research question did not require quantitative statistical data to answer. Because of the exploratory nature of this study and considering the lack of information about innovation of SMEs in developing countries (Xie et al., 2013), qualitative research was more suitable than quantitative or mixed research for this study.

I used a multiple case study as a research design for this study. Yin (2017) suggested using a multiple case study design when the researcher presents more than one case in the study in the absence of clear boundaries between the phenomenon and the context. In addition, case study design is suitable for collecting rich data using how and why questions about a current phenomenon on which the researcher has no control (Yin, 2017). Researchers use phenomenological research design to gain an accurate understanding of the essence of a lived experience in the words of those who went 
through it (Moustakas, 1994). Therefore, phenomenological research design was not suitable for this study. Similarly, ethnography was not appropriate for this study because ethnography addresses the behavior, customs, beliefs, and behaviors of a specific cultural group (Percy, Kostere, \& Kostere, 2015). Narrative inquiry is an in-depth interview where the researcher collects life stories of the participant (Marshall \& Rossman, 2016). Since the life stories did not contribute to the subject of this study, narrative inquiry was not a suitable design for this study.

\section{Research Question}

What strategies do SME managers use to implement innovation in their organizations to meet performance goals?

\section{Interview Questions}

The participants answered the following questions during the interview:

1. What strategies are you using to implement innovation?

2. What strategy did you find worked best to facilitate innovation implementation?

3. What was the impact of innovation in enabling your organization to meet its performance goals?

4. What resources that your company has that enabled the implementation of innovation?

5. How did you see the importance of competencies for the implementation of innovation?

6. How did you compete with other companies in the market? 
7. What additional information would you like to share about innovation implementation strategies in SMEs?

\section{Conceptual Framework}

The resource-based view (RBV) theory was the basis for developing a conceptual framework for this study. Edith Penrose developed the theory of the growth of the firm in 1959 (Penrose, 1959). Later, Wernerfelt (1984) introduced the term RBV and opined that companies could perform above average by acquiring critical resources that other firms do not have. Barney (1991) refined the theory of the firm and the RBV theory by defining specific characteristics for critical resources. The underlying constructs of the RBV theory are (a) resources, (b) competencies, and (c) long-term performance improvement by creating a sustainable competitive advantage (Barney, 1991). The RBV theory is especially applicable to SMEs because the degree of innovativeness depends on the firm resources (Hadjimanolis, 1999). In addition, Baumane-Vitolina and Cals (2013) argued that the RBV theory could facilitate the study of innovation in firms. As applied to this study, the RBV theory holds that I would expect the propositions advanced by the theory to allow participants to explore strategies that SME managers used to implement innovation in their organizations to meet performance goals.

\section{Operational Definitions}

Competitive advantage: The ability of the firm to earn returns on investment consistently above the average for the industry (Porter, 1996). 
Core competencies: The learning capacity of the firm and the ability of the firm to coordinate varied production skills and multiple technology streams (Hamel \& Prahalad, 1990).

Dynamic capability: A company's ability to transform resources, processes and capabilities at its disposal to address a rapidly or moderately rapidly changing environment (Wójcik, 2015).

Enterprise special competencies: Are enterprise capabilities to renovate existing resources, produce new knowledge on the existing basis, observe new business opportunities, and produce innovations (Baumane-Vitolina \& Cals, 2013).

Innovation: The economic application of an invention achieved through a money-making transaction that involves the new device, process, product, or service (Bertoni \& Tykvová, 2015).

\section{Assumptions, Limitations, and Delimitations}

\section{Assumptions}

Assumptions include suppositions believed to be true without clear proofs (Leedy \& Ormrod, 2015). Several assumptions underlined this study. The first assumption was that the participants would answer the interview questions honestly and accurately. The second assumption was that the participants would possess good knowledge about their companies. The last assumption was that semistructured interviews were suitable tools for answering the research question. 


\section{Limitations}

Limitations are factors beyond the control of the researcher (Yin, 2017).

Researchers should highlight the limitations of their qualitative studies the same way they report the findings (Elo et al., 2014). This study had three limitations. The first limitation was related to the study sample. As the top innovative SMEs in Dubai would be the focus of this study, the innovation implementation strategies may not apply to all SMEs operating in Dubai or the UAE. The second limitation was the degree to which the findings could apply to all SMEs in different sectors given that none of the SMEs in the sample were medium enterprises. The third limitation was the dependency of this study on a single researcher with limited experience in qualitative research.

\section{Delimitations}

Bilbo, Bigelow, Escamilla, and Lookwood (2015) defined delimitations as the time, location, or context boundaries that a researcher puts for a qualitative study. Delimitations of this multiple case study were the location, the sample size, and the sample group. I studied SMEs operating in Dubai. I restricted the study to four SMEs. Participants were SME managers who implemented innovation in their firms to meet performance goals.

\section{Significance of the Study}

SMEs constitute approximately $90 \%$ of the total active firms worldwide (Shrirame \& Soni, 2015). This study is of value because its findings may contribute to local and global economic growth. Exploring successful innovation implementation strategies in SMEs can result in useful guidelines that SME managers can use to reach the 
performance goals of their SMEs. Obaji and Olugu (2014) argued that governmental policies are critical to improving business performance. Thus, the government of Dubai may benefit from this study by addressing key success factors for SMEs through policies and regulations.

\section{Contribution to Business Practice}

This study may contribute to the practice of business because SME managers may use the study results to improve the performance of their firms through the implementation of innovation. Hajar (2015) noted that innovation has a positive influence on the performance of the company. SME managers can increase the competitiveness of their SMEs by incorporating innovation into their organizations (Asare, 2014). SMEs represent an essential part of the economic growth in developing and developed countries (Niţescu, 2015). Despite the role that SMEs play in the local and global economy, few studies addressed the issue of innovation implementation in SMEs especially in developing countries (Xie et al., 2013). This study has particular significance because of the lack of studies that address the issue of innovation implementation in SMEs, especially for SMEs in emerging economies.

\section{Implications for Social Change}

The implications for positive social change include the potential to create significant jobs, protect the economy during downturns, and contribute to economic growth. SMEs have a positive impact on community development through the generation of the employment opportunities (McCann \& Ortega-Argilés, 2016; Qamruzzaman, 2015). SMEs employ around 50\% of the workforce in an average 
country (Ayyagari, Demirguc-Kunt, \& Maksimovic, 2014). Similarly, Ali, Rashid, and Khan (2014) stated that SMEs play a crucial role in creating employment opportunities and reducing poverty. Likewise, Çela and Gaspari (2015) stated that SMEs have a positive impact on economic growth, job creation, and social stability. In economic downturns, SMEs still create new jobs whereas large enterprises (LEs) make most of the layoffs (Ayyagari et al., 2014; Varum \& Rocha, 2013). An increase in the productivity of SMEs means a potential for an increase in Dubai's gross domestic product (GDP), an improvement in investment opportunities in Dubai, better working conditions for employees, and possibilities for expanding the operations of Dubai SMEs globally.

\section{A Review of the Professional and Academic Literature}

The purpose of this qualitative multiple case study was to explore strategies that some SME managers use to implement innovation in their organizations to meet performance goals. The overarching research question for this study was the following: What strategies do SMEs use for implementing innovation to improve performance? To answer this question, I conducted a qualitative multiple case study starting with SME managers from four different SMEs. Before conducting the study, I conducted a review of the literature that addressed the implementation of innovation in SMEs. Marshall and Rossman (2016) viewed the literature review as a conversation between the researcher and other researchers that serves to (a) provide a firm basis for the study, (b) demonstrate the researcher's knowledge about the topic, and (c) refine the research question. Through the review, analysis, and synthesis of the literature, I identified four main streams for the review: (a) SMEs, (b) innovation, (c) the RBV theory, and (d) innovation implementation 
strategies in SMEs. The first stream included the various definitions of SMEs, a

comparison between SMEs and LEs, the role of SMEs in the economic development, and the SME innovation in Dubai. The second stream included various definitions of innovation, types of innovation, the role of innovation in SME performance, and barriers against SME innovation. The third stream included different theories dealing with the implementation of innovation in SMEs with a primary focus on the RBV theory which formed the basis for the conceptual framework for this study. The fourth stream included the importance of having innovation as part of the business strategy of SMEs, the role of corporate culture, cooperation networks, and the view of innovation as an extension of imitation in China. I summarize the structure of the literature review in Figure 1.

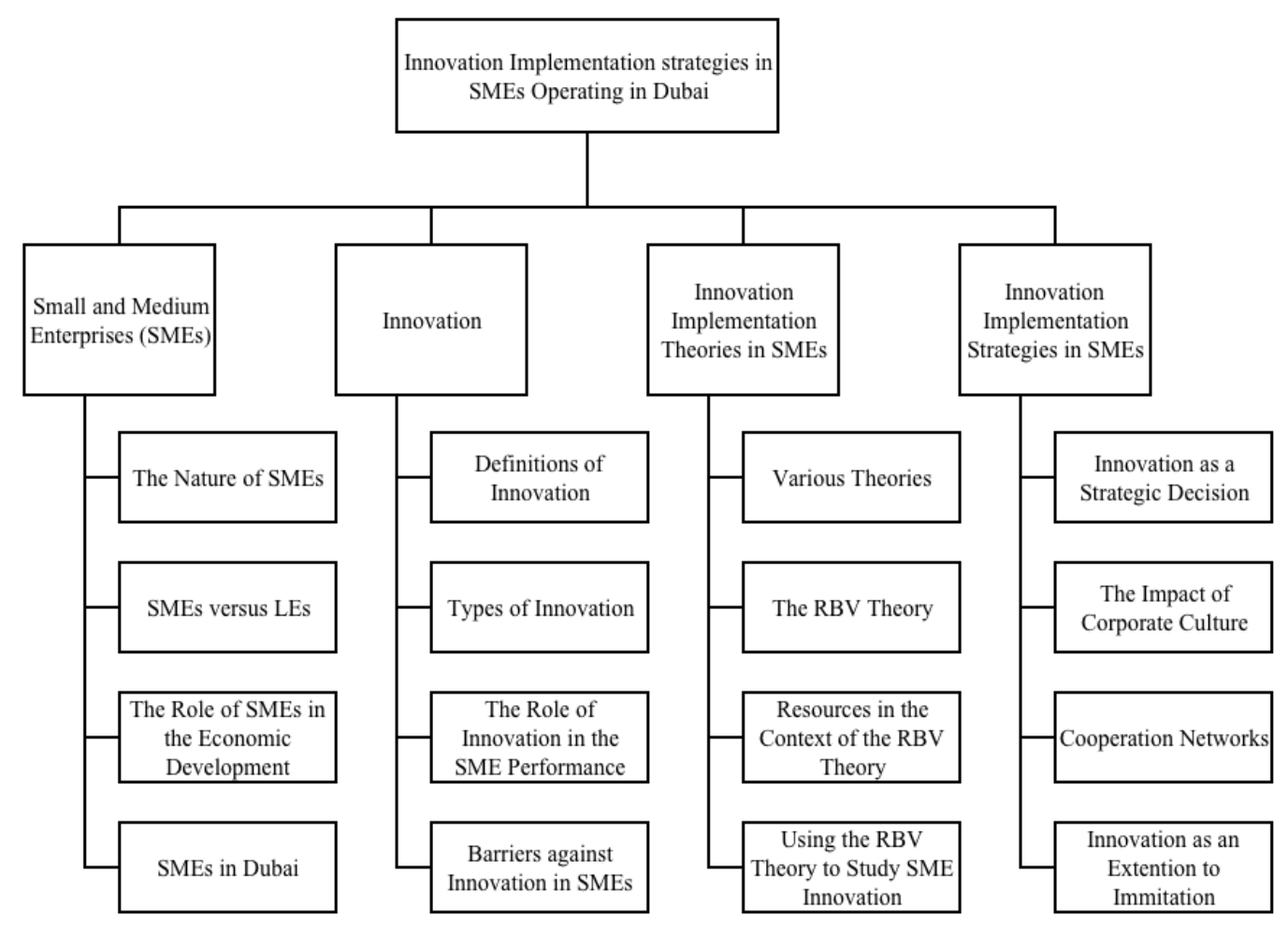

Figure 1. The structure of the literature review. 
To conduct a comprehensive review of the relevant and recent literature, I used academic journals, articles, books, reports, government publications, and websites. I used Google Scholar and several databases to search for relevant articles, such as Sage Premier, ProQuest, Business Source Complete, EBSCOHost, Emerald Management, and ScienceDirect. In the search for relevant literature, I used several keywords and phrases such as small business, small and medium enterprises, SME, innovation, performance, implementation strategies, barriers, $R B V$ theory, and resource-based view. In this literature review, I used 121 references that were a mix of seminal, governmental, and peer-reviewed. The number of resources that were either seminal or peer-reviewed published during or after 2014 was 109. These seminal or peer-reviewed publications represented $90 \%$ of the total references I used in this review.

\section{Introduction}

Economic development heavily relies on the success or failure of SMEs, and world economies are grappling with policy issues related to ways in which they can stimulate economic growth through the development of SMEs (Ndesaulwa \& Kikula, 2016). Innovation has been a key force driving competition in today’s chaotic environment, and researchers are struggling to create activities and initiatives that would lead to innovation at the organizational level (Olughor, 2015). SMEs are essential for economic growth because they provide employment opportunities and act as catalysts for economic growth through their innovative activities.

Despite the reports of how SMEs are driving countries' economies and enhancing people's lives, they still face many challenges that limit their growth (Asare, 2014). In 
the UAE, Schiliro (2015) found that SMEs face several challenges such as the access to funding from banks, the availability of qualified employees, and the weak technological infrastructures of the SMEs. In relation to the human capital, Organization for Economic Cooperation and Development (OECD, 2017) highlighted that SMEs face difficulties in identifying, recruiting, and keeping qualified and skilled employees. Regarding the financial difficulties, Nitescu (2015) listed 11 reasons behind the difficulties that SMEs face when trying to secure funding. Among the financial challenges are irregular patterns of earning, insufficient collateral, and the lack of SME tailored funds.

Many researchers have recorded the positive impact of innovation on SME performance. However, the performance of an SME is not solely dependent on innovation but is also an outcome of several factors in the business environment. Innovation is a necessary element of success in SMEs but is not sufficient for a business's survival and success (Ndesaulwa \& Kikula, 2016). In this literature review, I take a reflective approach to the various studies on how innovation affects the performance of SMEs across the world and how SME managers can benefit from implementing innovation in their firms.

\section{The RBV Theory}

Wernerfelt (1984) introduced the RBV of the firm. The theory of the growth of the firm which Penrose developed in 1959 was the basis of the RBV theory (Kor, Mahoney, Siemsen, \& Tan, 2016; Simba, \& Ojong, 2017; Woschke, Haase, \& Kratzer, 2017). Barney (1991) refined the RBV theory by defining specific characteristics for critical resources. Teece, Pisano, and Shuen (1997) introduced the concept of dynamic 
capabilities to indicate the importance of the firm ability to respond to a rapidly changing environment. Penrose, Wernerfelt, Barney, and Teece et al. contributed to the RBV theory as we know it today.

The theory of the growth of the firm. Edith Penrose developed the theory of the growth of the firm in 1959 (Penrose, 1959). Kor et al. (2016) argued that Penrose contributed both directly and indirectly to the fundamental concepts of the current RBV of the firm. Additionally, Baumane-Vitolina and Cals (2013) mentioned that the theory of the growth of the firm mandates both realization and utilization of resources as a condition for growth. Resource realization means the existence of the resources, and resource utilization means the way SME managers deploy the resources. Therefore, we can summarize Penrose view of the firm as the existence of proper resources and the correct utilization of these resources.

The RBV of the firm. Wernerfelt (1984) posited that the resources and the products of the firm are closely related although they seem different. Products need resources and resources make products. Firms should follow a balanced approach that includes the exploitation of existing resources as well as the development of new resources. Firms should have strategies for resource identification and resource combination (Wernerfelt, 1984). Firms can perform above average through identifying and acquiring a critical set of resources. Wernerfelt did not provide clearance about the method firms can follow to search for new resources or combine existing resources in different ways. 
The concept of VRIN resources. Barney (1991) opined that firms are bundles of resources. These bundles are different and difficult to transfer among firms which gives some firms competitive advantages over others. This new conceptual view of firms can explain the differences in performance among firms. Barney (1991) refined the theory of the firm and the RBV theory by defining specific characteristics for critical resources. In this refinement, Barney (1991) argued that firms could achieve and sustain their competitive advantage if they possess resources that are valuable, rare, inimitable and non-substitutable (VRIN). A firm that has a rare resource will have a competitive advantage over other firms (Barney, 1991). A firm that has a valuable resource will be able to capture business opportunities and alleviate threats (Sehnem, Roman, Sehnem, \& Machado, 2016). Valuable and rare resources are necessary but insufficient to provide a sustainable competitive advantage. Resources must also be inimitable and nonsubstitutable. Inimitable resources are those that other firms cannot copy in a perfect way. Non-substitutable resources are one or more resources that their created value cannot be obtained through any other different set of resources (Barney, 1991). A competitive advantage comes from implementing a unique value-creating strategy while sustained competitive advantage comes from implementing a unique value-creating strategy that other firms cannot duplicate (Barney, 1991). Therefore, competitiveness results from resource uniqueness while sustainability results from resource immobility.

Dynamic capabilities. Teece et al. (1997) introduced the term dynamic capabilities as a further addition to the RBV theory and the characteristics of critical resources. Firms that have dynamic capabilities can react to external changes by 
following new strategies to develop and reconfigure their resources (Teece et al., 1997). Similarly, Nada and Ali (2015) described dynamic capabilities as the firm's capacity to combine, build, and rearrange operational capabilities to adapt to the market. Wang and Ahmed (2007) opined that the dynamic capabilities are the highest order capabilities that constitute a significant factor in sustaining a long-term performance. Therefore, dynamic capabilities are a special group of skills and capabilities that enable firms to respond to external change, reconfigure resources for better performance, and sustain a long-term performance that is above average.

\section{Definition of Resources in the Context of the RBV Theory}

The VRIN model of strategic resources represents the fundamental requirements for a sustainable competitive advantage and above average performance. Eniola and Ektebang (2014) argued that resources are the major player in enabling firms to improve their performance. The differences in resources and their different utilization among firms can explain the differences in performance (Barney,1991; Genç, Özbağ, \& Esen, 2013). Furthermore, Norek (2014) argued that the resources than a company own decide the ability of the company to innovate. The way firms combine and utilize resources open the door for the role of competencies and innovation.

Different researchers provided different definitions and classification for resources in the context of the RBV theory. For example, Burton and Rycroft-Malone (2014) and Eniola and Ektebang (2014) classified resources as tangible and intangible. Nada and Ali (2015) considered resources as assets and capabilities. Conversely, Genç et al. (2013) mentioned that many researchers use the terms competence and capability 
interchangeably. Along the same line, Baumane-Vitolina and Cals (2013) highlighted that the terminology that appears in the literature describing the resources from the RBV perspective is confusing. They divided the resources into material resources, nonmaterial resources, and competencies. They further divided the competencies into basis competencies and special competencies. Despite the critical importance of resources in the RBV theory, the definition of resources remains ambiguous in the literature. Therefore, researchers should clarify the definitions and the classifications of the resources that suit the purpose of their studies.

Two groups of competencies attracted much attention in the literature. The first group is the core competencies. Hamel and Prahalad (1990) introduced the term core competencies stating that a core competency is the knowledge and the learning capacity of the firm. They argued that core competencies are combinations of competencies that should provide significant value to the customer, be competitively distinctive, and provide potential access to a wide variety of markets. Genç et al. (2013) opined that core competencies differ from resources and capabilities. Rahab, Anwar, and Priyono (2016) argued that core competencies have three dimensions: relationship, adaptation, and innovation. The second group is the dynamic capabilities. Teece et al. (1997) introduced the concept of dynamic capabilities to denote the importance of the firm ability to respond to a rapidly changing environment by renovating and combining its resources in novel ways. When developing dynamic competencies, a firm will be able to able to reconfigure its capabilities to respond to the changes in the environment (Lara \& SalasVallina, 2017). To simplify the nomenclature of the RBV theory, Wang and Ahmed 
(2007) introduced a four-level hierarchal model to summarize the resources, competencies, capabilities, and the relation between them. The four levels are:

Zero-order. Resources which are the building blocks of the capabilities of the firm. When these resources satisfy the VRIN criteria, they can lead to a competitive advantage.

First-order. Capabilities which can improve the firm performance when deploying the resources to achieve specific goals.

Second-order. Core capabilities which are bundles of resources and competencies that the firm assemble in alignment with the firm strategy. These bundles are essential for the firm's competitive advantage at a specific point in time. When the external environment changes, the core competencies can become obsolete. Core capabilities can become core rigidities if the firm fails to react to market changes.

Third-order. Highest level in the model which contains the dynamic capabilities. Dynamic capabilities are vital for the renovation, realignment, and rearrangement of the resources, capabilities, and core competencies to adapt and respond to market changes. Dynamic capabilities are responsible for the sustainable competitive advantage and the long-term performance of the firm.

The terminology that researchers use to describe and classify the resources, capabilities, and competencies is diverse. Nevertheless, I can make the following conclusions about the RBV theory and its nomenclature:

- Resources is a general word that can mean anything that the firm owns or has access to, and it can be tangible or intangible. The way a firm uses its 
resources determines its performance and sustainability. Critical resources are those that have the VRIN attributes.

- Capabilities and competencies appear many times to mean intangible resources.

- The efficient use of the existing resources requires core competencies while the continuous adaptation to external change through resource rearrangement requires dynamic capabilities.

- The ability to innovate is an intangible resource, a capability, or a special competence that can convert resources into profitability.

The nomenclature that describes the resources differs among researchers. In the context of the RBV theory, words like resources, capabilities, and competencies should have specific meanings. Because of the absence of unified definitions, researchers should define these terms to avoid misunderstanding.

\section{Using the RBV Theory to Study Innovation in SMEs}

The RBV theory is suitable for the study of the implementation of innovation in SMEs through analyzing how SMEs use their resources and capabilities to innovate. Carraresi, Mamaqi, Albisu, and Banterle (2016) considered the innovation as one of the SME capabilities. Rahab et al. (2016) considered the innovation as one of the three core competencies of SMEs. Likewise, Baumane-Vitolina and Cals (2013) opined that the ability to produce innovations falls under special competences which are difficult to reproduce by other firms. In addition, López-Cabarcos, Göttling-Oliveira-Monteiro, and Vázquez-Rodríguez (2015) argued that innovation is part of the business strategy that 
acts as a mediator for converting resources into profit. Hence, innovation acts as a mediator between resources and performance (De Zubielqui, Lindsay, \& O'Connor, 2014; Tamayo, Romero, Gamero, \& Martínez-Román, 2015). Drucker (1985/2014) defined innovation as the action that provides resources with a new capability to create wealth. Drucker's definition implies that innovation is a mediator that converts resources into value. The amount of value depends on the resources and the competence to combine these resources to create value. Since innovation is a vital competence for SMEs, the RBV theory is suitable for studying innovation in SMEs.

The resource scarcity in SMEs makes the RBV theory a suitable foundation for a conceptual framework for studying innovation in SMEs. Hadjimanolis (1999) argued that the RBV theory is especially applicable to SMEs because the degree of innovativeness depends on the resources of the firm. Similarly, Woschke et al. (2017) opined that the scarcity of resources in SMEs could limit their innovation abilities. Eniola and Ektebang (2014) argued that the RBV theory has specific importance in studying the significance of intangible resources such as managerial skills and experience. These managerial resources have special significance for SMEs because resource constraints hamper the acquisition of such competencies from outside the firm. As applied to this study, the RBV theory holds that I would expect the propositions advanced by the theory to allow participants to effectively explore strategies, perceptions, and experiences regarding innovation implementation in SMEs. 


\section{The Diffusion of Innovation Theory}

Everett Rogers introduced the diffusion of innovation (DOI) theory in 1962 (Rogers, 2003). According to Rogers, when using the DOI theory, the decision to adopt a new innovation passes through a five-stage process (Rogers, 2003). These five stages are awareness, persuasion, decision, implementation, and confirmation. Mamun (2018) used the DOI theory to study the adoption of innovation by Malaysian SMEs. The DOI applies primarily to decision making through the persuasion of individuals, not organizations (Rogers, 2003). However, Mamun (2018) argued that in SMEs one or a few individuals make decisions. Therefore, the DOI theory can apply to the innovation adoption in SMEs.

Comparing the DOI theory with the RBV theory, I choose the RBV theory as a basis of the conceptual framework of this study because it is more suitable for the subject of this study. For the DOI theory to apply to SMEs, the decision-making process must be in the hand of one or few individuals. This condition may apply to small size enterprises but may not apply to medium size enterprises. In addition, the decision path of the DOI theory implies an imitation of an existing product or process whereas the innovation under study is more about novelty rather than replication. On the other hand, the RBV theory applies to the innovation implementation in SMEs without the aforementioned assumptions of decision making authority or imitation. In addition, the inherent resource scarcity in SMEs makes the RBV theory a suitable lens that I can use to explore innovation implementation strategies in SMEs in light of resource scarcity. 


\section{The Nature of SMEs}

Various definitions of SMEs exist today that depend on several different criteria. A common and unified definition of SMEs does not yet exist (Berisha \& Pula, 2015; Ndesaulwa \& Kikula, 2016). Although the definitions differ among countries and organizations, there are common factors that determine the size of enterprises. For example, Ndesaulwa and Kikula (2016) asserted that the total number of employees, total turnover, and total investment are the basis for the definition of SME. Similarly, Petkovska (2015) mentioned that the definition of the enterprise size depends on the number of employees, annual revenue, total assets, and net profit. Katua (2014) mentioned that the definition of SMEs depends on the number of employees, the revenue, or the size of the balance sheet. The various definitions of SMEs all aim at deciding on a suitable criterion to determine the size of firms. Firms should have a ceiling for the number of employees and the annual revenue to quality as SMEs. However, having two or more determinants for the classification of firms can create disparities in the classifications of SMEs among countries and global organizations.

Different governments, banks, organizations, institutions, and statistical agencies have different definitions of SMEs. For example, in the United States and Canada, an SME can have up to 500 employees (Katua, 2014). In the European Union, an SME employs less than 250 employees with a maximum annual revenue of 50 million euros and/or a maximum total asset of 43 million euros (European Commission, 2014). However, some European countries have different definitions for SMEs. For example, an SME in Germany can have up to 250 employees while in Belgium the number of 
employees should be less than 100 (Katua, 2014). Another case of the absence of a common definition of SMEs is Pakistan. In Pakistan, the State Bank, the Federal Bureau of Statistics, and the Provincial Labor Departments use different definitions of SMEs (Syed, Ahmadani, Shaikh, \& Shaikh, 2012). Each government or organization can have its own definition of an SME. These differences can cause misalignment among the efforts to support SMEs. A unified criterion for defining SMEs can facilitate the study of performance improvement strategies in SMEs by creating significant associations within the literature.

In addition to the number of employees and the financial factors that determine the enterprise, the SME definition also depends on the sector in which the SME operates. Katua (2014) mentioned that the rationale behind this is to measure the enterprise size with respect to the sector and the market. For example, an SME in the manufacturing sector in Dubai can have employees up to 250. At the same time, an SME in the trading sector cannot have more than 75 employees (Dubai SME, 2014). Defining SMEs based on the sector provides a logical segregation of SMEs. However, there should be a clear definition for each sector to avoid further confusion. Such a segregation by sector does not contradict with a unified definition of SMEs. The unified definition can include the sector of operation as part of the criteria.

Having a common and clear definition for SMEs allows better monitoring of the performance of this critical sector and meaningful comparisons between countries or regions (Berisha \& Pula, 2015). Similarly, Eniola and Ektebang (2014) argued that the absence of a common definition of SMEs complicates the task of comparing the SME 
performance among countries or regions. The absence of a unified definition of SMEs impacts the eligibility criteria for support programs that can benefit SMEs. A unified criterion for defining SMEs can facilitate the study of performance improvement strategies in SMEs. Without a common definition, researchers should provide their classification of SMEs in each study in order to view the results in the correct perspective.

\section{SMEs Versus LEs}

The main differentiator between SMEs and LEs is the size of the enterprise. LEs and SMEs are names that stem from the number of employees, annual revenue, and assets. The definition of the size of the enterprise differs among countries, regions, institutions, and organizations. In addition, the definition can differ among sectors with different market sizes.

Besides the company size, SMEs and LEs differ in other factors such as ownership structure, ease of funding, and flexibility. Halme and Korpela (2014) opined that the ownership structure of SMEs differs from that exhibited by LEs. SMEs are often family-owned businesses with a small number of owners while LEs are often publiclyowned companies (Ndesaulwa \& Kikula, 2016). Because of their flexibility, SMEs have more potential to innovate than LEs (Halme \& Korpela). Although SMEs are significant contributors to growth, it is more difficult and costly to secure funding compared to LEs (Nitescu, 2015). Banks often prefer to lend to LEs more than SMEs because of the high risk associated with SMEs (Paulet, Parnaudeau, \& Abdessemed, 2014). The difficulties that SMEs face in obtaining funds add to their inherent resource limitations. At the same 
time, the capacity of SMEs to innovate increases the potential competitiveness and performance of SMEs. Governments, organizations, and regulatory bodies can support SMEs by easing the funding taking into consideration the risks and the potential gains that SMEs can bring to the economy.

SMEs have several disadvantages compared to LEs such as the possibility of bankruptcy, low salaries, and weak competitive advantages in international markets (Petkovska, 2015). In terms of innovation, SMEs have more potential to innovate than LEs because of their fast decision-making process (Ndesaulwa \& Kikula, 2016). Furthermore, Petkovska (2015) argued that SMEs could develop new products or services faster than LEs. Because of the small organizational structures of SMEs, SME managers can make a fast decision on resource utilization (Halme \& Korpela, 2014). Similarly, Deshati (2016) argued that SMEs have the advantage of faster innovation implementation compared to LEs because of their shorter lines of communication, relatively informal decision making, and their flexibility. On the other hand, Prajogo and McDermott (2014) argued that SMEs could not accumulate the required knowledge to innovate because of the resource limitations. Furthermore, resource limitations can cause many SMEs to avoid risky activities such as innovation because they cannot afford to fail (Sağa, Sezena, \& Güzela, 2016). Because of the abundance of human and financial resources, LEs are in a better position to invest in new ideas compared to SMEs (Wikhamn, Armbrecht, \& Wikhamn, 2018). Although SMEs face many challenges because of their resource limitations, the relative advantage that SMEs have in terms of innovation capability allows them to compete against LEs. 
The relationship between SMEs and LEs is not entirely competitive. A strong network and body of SMEs plays a major role in supporting the activities of LEs, including fulfilling many of the peripheral tasks that LEs may not be able to address efficiently. Moreover, SMEs present a growth opportunity for LEs that can fund and acquire small businesses to grow their own business and maintain the relevance of their offerings (Foreman-Peck \& Nicholls, 2013). The acquisition for SMEs by LEs creates a potential exit opportunity for entrepreneurs and provide them with additional sources of capital to start new innovative SMEs, thus beginning a new phase of the growth cycle.

\section{The Role of SME in Economic Development}

SMEs are major contributors to the economy in both developed and developing countries. Nitescu (2015) stressed the crucial role that SMEs play in the development of national economies. Eniola and Ektebang (2014), Asare (2014), and Qamruzzaman (2015) described SMEs as the engine of the economic growth. The role of SMEs in the economic development covers several aspects and stems from various factors such as job creation, poverty reduction, and contribution to the GDP (Jitmaneeroj, 2016; Mabhungu \&Van Der Poll, 2017; Valaei, Rezaei, \& Ismail, 2017; Zafar \& Mustafa, 2017).

Although SMEs' optimum potential is still unexploited, they have been instrumental in the provision of employment opportunities and have contributed to the gross domestic products of both developed and developing countries (Olughor, 2015). As the backbone of economic development, SMEs should be the center of the attention of authorities and regulatory bodies. Governments should help SMEs to overcome their resource limitations to improve their competitiveness and performance. A strong SME sector 
ignites innovation, create new jobs, reduces unemployment, improves the economic state, and alleviate poverty.

SMEs are the majority of enterprises all over the world. Shrirame and Soni (2015) declared that SMEs represent $90 \%$ of the enterprises in most countries. Similarly, Petkovska (2015) mentioned that SMEs represent around $90 \%$ of all businesses in the global economy with an employment share higher than $60 \%$ in the private sector. Similarly, Çela and Gaspari (2015) mentioned SMEs represent nine out of 10 enterprises in the European Union. Shrirame and Soni (2015) reported that SMEs represent a significant part of local and global economies by constituting around $90 \%$ of the total firms worldwide. Bayarçelik, Taşel, and Apak (2014) reported that SMEs constitute 99\% of the total enterprises in Japan, France, and Italy. Asare (2014) mentioned that SMEs in Ghana represent $92 \%$ of the registered companies. The Small Business Administration (SBA) reported that there are more than 28 million small businesses in the United States which represent $99.7 \%$ of the total national businesses (U.S. SBA, 2015). A similar scale exists in Dubai where SMEs constitute 95\% of the enterprise population (Dubai SME, 2014). Being the majority of enterprises in the world (Shrirame \& Soni, 2015), SMEs deserve high attention. The support that governments give to SMEs can touch a large number of employers, employees, and population. Investing to sustain a healthy SME sector may benefit the whole society.

SMEs are significant contributors to the GPDs of countries. For example, Katua (2014) reported that the SMEs' contribution to the national GDP is $60 \%, 57 \%$, and $55 \%$ in China, Germany, and Japan, respectively. Furthermore, SMEs in Singapore and South 
Korea contribute $49 \%$ and 55\% to the national GDP, respectively (Pulka, Ramli, \& Bakar, 2018). In all the OECD countries, SMEs contribute between $50 \%$ and $60 \%$ of the national GDP of each country (OECD, 2017). The contribution of SMEs to the GDP is not less than the contribution of LEs.

In addition to being the largest population among enterprises and a strong contributor to GPDs, SMEs are major employers and job creators. Katua (2014) argued that SMEs are the leading employer in the world. The National Research Council of Italy, Research Institute on Sustainable Economic Growth (CNR-IRCRES) (2018) reported that SMEs employ a large portion of employees in most countries. Olughor (2015) reported that SMEs employ about $75 \%$ of the workforce in any country. In the European Union, SMEs employ two out of three employees (Çela \& Gaspari, 2015; Katua, 2014). SMEs in Dubai employ $42 \%$ of the workforce (Dubai SME, 2014). In economic downturns, SMEs still create new jobs whereas LEs make most of the layoffs (Ayyagari et al., 2014; Varum \& Rocha, 2013). Job creation and economic growth lead to improving the living conditions and the reduction of poverty (Subhan, Mahmood, \& Sattar, 2014). Moreover, Eniola and Ektebang (2015) highlighted that SMEs serve as incubators for entrepreneurs. Therefore, SMEs play a critical role in improving the living conditions, reducing poverty, and reducing unemployment through creating new jobs.

\section{The Status of SMEs in Dubai}

Dubai is one of the seven emirates that constituted the United Arab Emirates (UAE) in 1971. The United Arab Emirates is a rich country with a high dependency on Oil and Gas as a major source of economic growth. The UAE and its five neighboring 
countries of Bahrain, Kuwait, Saudi Arabia, Qatar, and Oman established the gulf cooperation council (GCC). Crude oil is the main element of the GCC countries' economies (Louis \& Balli, 2014). The GCC countries have $36 \%$ of the world reserve of crude oil which contributes around $46 \%$ to the combined GDPs of the six countries (Miniaoui \& Schilirò, 2017). The high dependency on crude oil exports can threaten the economic growth and sustainability because of the volatility of the oil prices (Miniaoui \& Schilirò, 2017). Furthermore, Louis and Balli (2014) argued that changes in the oil prices may result in unexpected effects on the economies of the GCC countries. Therefore, Cherif, Hasanov, and Zhu (2016) suggested that the GCC countries should diversify their economies to achieve sustainable growth. The high dependency on a single source of revenue creates high risks which may have negative impacts on the GPD. The decline in oil prices that started in 2014 is still impacting the GCC economies who lost around 50\% of the oil revenue. The GCC countries should put a strategy to reduce the dependency of their economies on crude oil by diversifying their revenue streams and encouraging the private sector for active participation in economic growth. Such diversification creates a resilient and stable economy.

While the GCC countries have poor performance in innovation, Miniaoui and Schilirò (2017) opined that these countries should encourage the private sector to improve competitiveness and create jobs. Hana (2017) recommended that the government of the UAE should become more agile to catch new opportunities, embrace innovation, learn from failures, be open to new ideas, and should encourage the implementation of new ideas. Miniaoui and Schilirò (2017) opined that innovation is a 
fundamental driver for economic diversification and an essential element in stimulating economic growth. Furthermore, they asserted that innovation policies should target SMEs in particular since SMEs are the backbone of the GCC economies. The UAE government announced that each ministry would invest $1 \%$ of its budget in innovation (Hana, 2017). This step came to improve innovation in which the UAE and all the GCC countries have poor performance (Miniaoui \& Schilirò, 2017). To reduce their reliance on the volatile crude oil revenues, the GCC countries need to diversify their economic activities and revenue streams. One of the best ways to diversify is to encourage innovation, especially in SMEs. By spending $1 \%$ of the annual budget of the UAE on innovation, encouraging results may start to appear within a few years.

SMEs in Dubai have a considerable contribution to the economy of Dubai and the UAE. Dubai SMEs constitute $95 \%$ of the enterprise population, employ $42 \%$ of the employees, and contribute $40 \%$ of Dubai's GDP (Dubai SME, 2014). Political stability, low tax, and high quality of life encouraged investors and skilled employees to come to Dubai and start their businesses and careers (Hana, 2017). Nevertheless, Schiliro (2015) found that SMEs face several challenges such as the access to funding from banks, the availability of qualified employees, and the weak technological infrastructures of the SMEs. SME managers can overcome these challenges and improve their organizations' performance through implementing innovation. Indeed, Al-Ansari et al. (2013) found that innovation had a positive impact on the performance of SMEs in Dubai. However, the authors did not study how SME managers can utilize innovation to improve their organizations' performance. Despite the considerable contribution of SMEs to Dubai 
economy, only 13\% of Dubai SMEs implement innovation (Dubai SME, 2014). There seems to be a good room for improvement in the performance of Dubai SMEs taking into consideration the positive impact of innovation on performance and the absence of studies that address the innovation implementation in SMEs.

\section{The Definition of Innovation}

The definition of innovation was always complex, and the last decade added to the confusion because of its characteristic rapid changes in the political, social, and technological facets of life. For example, CNR-IRCRES (2018) described innovation as being simultaneously simple and complex. Popa, Preda, and Boldea (2010) listed 17 different definitions of innovation. Manuylenko, Mishchenko, Bigday, Putrenok, and Savtsova (2015) defined innovation as a change in diverse variations and an outcome. Bertoni and Tykvová (2015) introduced another definition of innovation as the economic application of an invention through a financial transaction that involves the new device, process, product, or service. Also, McKinley, Latham, and Braun (2014) described innovation as any new product, service, or process that departs considerably from an existing product, service, or process architectures. Rua and França (2017) described innovation as the encouragement of creativity and new ideas that can result in new processes, services, or products. Omerzel and Jurdana (2016) defined the ability to innovate as the successful implementation of new ideas, processes, or products. To innovate is to implement a good idea in an efficient way (Halim, Ahmad, Ramayah, \& Hanifah, 2014; Tehseen, Sajilan, Adaha, \& Abadi, 2016). In addition, Grzegorz and Robert (2018) opined that searching for ideas is the first step of the innovation process. 
Companies cannot create value without the successful implementing the new ideas. The complexity and diversity of the term innovation may be the main reasons behind the large number of the definitions of innovation.

Despite the diversity of the various definitions of innovation, there are common characteristics that repeat in these definitions. First, innovation includes change. The degree of change determines the type of innovation such as incremental and radical. Second, the change should introduce an improvement. If a change does not cause an improvement to an existing product, service, or process, it will not be an innovation. Third, the change should create an added value for the user. Fourth, innovation goes beyond the mere introduction of ideas to the implementation and the realization of the added value. Therefore, I can describe innovation as the implementation of change that introduces improvement and provides an added value to the user.

\section{Types of Innovation}

The nature of innovation an SME implements can fall under several types of innovation. Talegeta (2014) had a three-dimensional view of innovation. Innovation can be technological or non-technological, and it can target the product, process, market, or the organization in either an incremental or a radical way (Talegeta, 2014). These three dimensions are not mutually exclusive. For example, a firm can introduce a new product as a radical technological product innovation. In addition to these three dimensions, there are other dimensions as well. Aziati, Tasmin, Jia, and Abdullah (2014) opined that business innovation could focus on administration innovation, management practices, or organizational structure. Furthermore, Zarei and Baghban (2014) mentioned two more 
types of innovation: open innovation and closed innovation. The various classifications of innovation add to the complexity of studying and measuring innovation.

Open versus closed innovation. Open and close innovation are two common methods for innovation in SMEs. Zarei and Baghban (2014) highlighted that open innovation is an emerging approach whereby SME managers search for ideas both inside and outside the organization. Mercandetti, Larbig, Tuozzo, and Steiner (2017) considered open innovation as an intelligent way of utilizing all possible internal and external resources to achieve success. Similarly, Freel and Robson (2017) opined that businesses who implement open innovation must employ internal and external sources of innovation rather than just depending on internal resources. Carraresi at al. (2016) opined that SMEs could follow open innovation through cultivating partnerships to increase their resources. The measure of openness is the tendency to cooperate with other institutions or companies (Stanisławski, \& Lisowska, 2015). On the other hand, closed innovation implies independence and strict control throughout the whole cycle of innovation from idea generation till after sale support (Zarei \& Baghban, 2014). Open and closed innovation can benefit SMEs. Closed innovation utilizes a do-it-your-self approach whereas open innovation uses partnerships and collaborations with other firms. Managers of SMEs need to determine how and when to use each type.

The choice between open and closed innovation is a strategic decision for SMEs (Love \& Roper, 2015). As with most decisions, there are both advantages and disadvantages in the choice that an SME manager makes. Open innovation can reduce the possible risks of innovation by spreading the cost and the risks among a number of 
firms instead of a single firm (Petkovska, 2015; Zarei \& Baghban, 2014). Moreover, the external collaboration with other firms can provide SMEs with the resources they need through sharing and without the need to acquire them (Carraresi et al., 2016). Although open innovation offers significant advantages to SMEs, excessive openness can have a negative impact on performance (Hossain \& Kauranen, 2016). Another concern that comes with open innovation is the data exposure and the loss of knowledge to competitors (Freel \& Robson, 2017; Laursen \& Salter, 2014). Open and closed innovation have advantages and disadvantages. Ahmed, Halim, and Ahmad (2018) argued that a combination of both open and closes innovation will result in a superior performance improvement compared to relying on open innovation or closed innovation separately. SMEs should strike a balance between open and closed innovation. Collaborating with a high number of firms can incur high costs while going towards closed innovation can result in lost opportunities. Therefore, a balanced between open and closed innovation is a key success factor for SMEs with limited resources.

Incremental versus radical innovation. The amount of novelty determines the type of innovation as either incremental or radical. Papetti, Marilungo, Gregori, and Germani (2016) viewed incremental innovation as a continuous enhancement to an existing process whereas radical innovation is a complete departure from an existing process to a better new one. Similarly, Zarei and Baghban (2014) argued that incremental innovations are marginal changes in response to a demand while radical innovations are the outcome of a new expression of a problem. SME managers should 
decide the amount of novelty they seek and the amount of investment they are willing to spend in pursuit of innovation.

SME innovation can be either incremental or radical. Rexhepi (2014) opined that SMEs should follow different strategies to be able to produce radical or incremental innovations. For example, incremental innovations require a more formal internal process compared to radical innovations. Aziati et al. (2014) found that the majority of SMEs innovations are incremental rather than radical. Pinget, Bocquet, and Mothe (2015) highlighted that incremental innovation requires much fewer skills and resources compared to radical innovation. The focus of SMEs on incremental rather than radical innovation may be because of the resource limitation which is a primary characteristic of SMEs. Resource limitations affect the novelty that SMEs produce.

Product, process, market, and organizational innovations. OECD and Eurostat (2005) defined innovation as a new or improved implementation of a product, a process, marketing method, or an organizational method for improving the business practices. Ukpabio, Oyebisi, and Siyanbola (2017) considered these four types as outcomes of innovation. Therefore, product innovation, for example, aims at improving a product or service. Similarly, process innovation aims at improving a particular process, and so on. Before 2005, the OECD has its focus on the technological products and processes (OECD \& Eurostat, 2005). Product and process innovations related mainly to technological development. Therefore, OECD and Eurostat (2005) considered that technological innovations manifested in product and process innovations whereas nontechnological innovations appeared as marketing or organizational innovations. The 
classification of innovation into product, process, market, and organizational can create enough segregation between the innovation type so that SME managers can implement specific strategies to target specific types of innovation.

The relations among the different classifications of innovation. The different classifications of innovation are not mutually exclusive. On the contrary, there appear to be different levels of association between these innovation types. For example, Hossain and Kauranen (2016) argued that closed innovation is appropriate for incremental innovation whereas open innovation is suitable for radical innovation. On a different front, Hassan, Shaukat, Nawaz, and Naz (2013) found that organizational innovation had a strong influence on process innovation in particular. Hassan et al. (2013) found that marketing innovation leads to product innovation. Similarly, Boachie-Mensah and Acquah (2015) argued that marketing innovation affects the product design, packaging, and pricing. The classification of innovation types is essential for understanding the impact each type can have on the performance.

\section{The Role of Innovation in Improving the Performance of SMEs}

Innovation is a significant element for SME survival and growth (Farsi \& Toghraee, 2014; Kuo \& Chao, 2014). Similarly, Susanto and Wasito (2017) and Hajar (2015) noted that innovation has a positive influence on the performance of the company. The long-term success of SMEs is dependent on their innovation (Kotey, 2014; Saunila, 2016; Schiliro, 2015). When paired with a good strategy, an innovative culture forms a superior approach to improve the performance in SMEs. Boachie-Mensah and Acquah (2015) considered innovation to be a corporate strategy that can lead to a competitive 
edge through producing better products, improving the market performance, and building a good reputation. Hervas-Oliver, Ripoll-Sempere, and Moll (2016) mentioned that innovation could provide an advantage in creating new products, acquiring a more significant market share, improving quality, increased flexibility and production capacity, and reducing costs. Although it is not enough to guarantee SME survival and success, innovation is a necessary element for the success of SMEs (Ndesaulwa \& Kikula, 2016). Therefore, SME managers should include innovation as an integral part of their business strategies.

Karabulut (2015) and Subhan et al. (2014) found a positive correlation between process innovation and the financial performance. Innovation is an essential factor in the promotion of economic efficiency of both SMEs and the countries in which these SMEs operate (Ukpabio et al., 2017). Furthermore, Ukpabio et al. (2017) found that process innovation can improve the performance of enterprises in developing countries which leads to growth and development. Similarly, innovation can improve products and processes within SMEs (Padilha \& Gomes, 2016). Through innovation, SMEs can differentiate their products and services and can enhance the efficiency of their business operation (Asare, 2014). Along the same line, Ndesaulwa and Kikula (2016) argued that it is only innovative companies that will remain effective in serving customer needs and survive turbulent and risky environments in the long run. SMEs with the aptitude to innovate can react to challenges within the business environment quick enough to utilize new products and opportunities within the market better than those that do not innovate. Innovation is a survivor kit that SMEs can use to remain alive and compete. 


\section{Barriers Against SMEs Innovation}

The implementation of innovation in SMEs is not a straightforward process. Numerous barriers stand between the SMEs and the benefits of innovation. Barriers to innovation can be either internal or external (Asare, 2014; Bozkurt \& Kalkan, 2014; Heslina, Payangan, Taba, \& Pabo, 2016; Tehseen et al., 2016). Internal barriers arise within the company such as the lack of management experience and poor employee skills (Bozkurt \& Kalkan, 2014; Heslina et al., 2016). Likewise, Tehseen et al. (2016) considered the lack of skills, abilities, and knowledge as internal barriers. In addition, Deshati (2016) opined that internal barriers include inadequate resources and the lack of expertise. On the other hand, Bozkurt and Kalkan (2014) mentioned that external barriers arise from external factors in the business environment. Tehseen et al. (2016) considered the market forces and the government regulations as external barriers. Similarly, Asare (2014) considered access to technology providers, macroeconomic conditions, lack of funds, and regulations as external barriers.

Deshati (2016) found that the high cost of innovation, market instability, and inadequate protection of innovation are the major barriers to SME innovation. Skawińska and Zalewski (2014) stressed that the absence of adequate regulation for the intellectual property (IP) protection could hamper innovation. In addition, Jones and Hooper (2017) found that the major barriers were risk avoidance, leadership mindset, and lack of funds. At the same time, Asare (2014) found that financial constraints, lack of skilled employees, poor infrastructure, lack of information technology knowledge, and market regulations are the main innovation barriers. Kotey and Sorensen (2014) found 
that poor infrastructure, lack of skills, access to funds, and political instability are common barriers to innovation. In addition, Lewandowska (2014) considered that poor SME financials and knowledge base as the main obstacles to innovation. In sum, the main factors that can discourage SME innovation are the lack of funds, poor knowledge, risk avoidance, market instability, weak IP protection regulations, and inadequate infrastructure. SME managers should try to overcome the internal barriers such as poor knowledge and risk avoidance while governments and regulatory bodies should work on the external barriers such as the infrastructure and the IP protection regulations.

Barriers against SME innovation causes many SMEs to struggle in implementing innovation and in reaping the expected innovation benefits. Leber, Bastic, and Buchmeisteri (2014) opined that the major obstacle to innovation is the lack of knowledge and the shortage of skills about the innovation management and implementation. Similarly, Norek (2014) and Xie et al. (2013) argued that the innovation is SMEs does not produce the expected results because of the inefficient implementation. Individual SMEs may not have enough influence to remove the innovation barriers and become innovative. Governments should create regulations that foster and protect innovation. SMEs need to acquire new knowledge through employing skilled personnel, training their existing employees, or through establishing cooperation networks for resource sharing.

\section{The Role of SME Managers in Innovation and Culture Change}

Innovation management is a critical area of study because of its contribution towards the enhancement of the competitive advantage. Deshati (2016) highlighted that 
SME managers employ the innovation management to remain competitive and achieve their financial goals. Therefore, SME managers should be capable of analyzing the market trends to identify needs, foresee changes, and look for new opportunities (Rua \& França, 2017). To that end, SME managers should make clear strategic decisions about their innovation strategies (Woschke et al., 2017). Likewise, Shafique and Kalyar (2018) opined that leaders with clear vision can stimulate the employees to innovate and go beyond what is required from them. For example, SMEs should choose between acquiring new resources and rearranging the existing ones. In addition, SMEs should choose between implementing an incremental and a radical innovation. Therefore, SME managers should exert deliberate efforts to foster and manage the innovation within their firms rather than dealing with innovation on an ad hoc basis.

For SMEs to become and remain innovative, it is mandatory that SME managers seek to embed innovation within the corporate culture. Maher (2014) argued that the organizational culture is a major factor which affects the pace of innovation. Similarly, Schiliro (2015) stressed that innovation is about culture and mindset more than anything else. Similarly, Szymańska (2016) argued that organizational culture is the foundation of all the processes within the organization that can play a role in supporting or obstructing innovation. In addition, Zhai et al. (2018) argued that SME managers need to promote the spirit of innovation and risk tolerance within their firms. Likewise, NaranjoValencia, Jiménez-Jiménez, and Sanz-Valle (2016) argued that the organizational culture relating to people and behavior can either encourage or hamper innovation. Therefore, innovation implementation is not subject to the sole decision of the SME manager. 
Managers and employees should contribute willingly to make innovation a part of the corporate culture.

SME managers should work on changing the way they and their employees think and act so that innovation becomes part of the company culture. Maher (2014) mentioned seven dimensions of innovative culture which are goals, relationships, tools, rewards, knowledge, risk-taking, and resources. Padilha and Gomes (2016) found that open corporate culture, creativity encouragement, flexible working arrangements, multifunctional teams, reward, recognition, and access to information can facilitate the implementation of innovation. The employees are the ones who will implement the innovation. Therefore, SME managers should direct a major part of their efforts towards their employees.

\section{Innovation as an Extension to Imitation}

Yu, Yan, and Assimakopoulos (2015) argued that innovation is not the direct opposite of imitation. Luo and Chanaron (2017) posited that the firm age and size determine its innovation capability and innovation strategy. Lee and Tang (2018) suggested that firms may utilize innovation, imitation, or both to survive and grow. The three different scenarios are visible in China who had a long history of imitation and a rising trend of innovation. Yu et al. (2015) found that SMEs in China started as imitators utilizing their low-cost advantage to manufacture competitive products. The change in the Chinese government policy regarding counterfeit products moved the strategic orientation of the SMEs away from imitation towards innovation. Yu et al. (2015) segregated this transition into four phases which are pure imitation, learning from the 
original equipment manufacturers, imitative innovation, and original innovation. Pure imitation cannot secure a good performance in the long term. The low cost of production is not a sustainable competitive edge. The only way for SMEs in China to have a sustainable competitive advantage is to move quickly to the original innovation phase.

\section{Cooperation Networks to Overcome Resource Limitations in SMEs}

The inherent resource limitations of SMEs triggered the formation of cooperation networks that allow SMEs to share resources and implement open innovation. Salisu and Abu Bakar (2018a) argued that despite the clear positive impact of innovation on the performance of SMEs, resource limitation stands as a barrier against innovation for many SMEs. To overcome this barrier, Salisu and Abu Bakar (2018a) found that strategic alliance can improve the innovation performance of SMEs. Along similar lines, Foghani, Mahadi, and Omar (2017) described a cooperation network as a group of companies with common challenges who work together to achieve an economic goal that they cannot reach individually because of their resource limitations. The degree of innovativeness of SMEs depends on the available resources (Hadjimanolis, 1999; Woschke et al., 2017). The innovation ability of SMEs decreases because of the risk aversion strategy that SME managers choose in order not to fail (Sağa et al., 2016). In addition, Petkovska (2015) argued that cooperation can reduce the possible risks of innovation by spreading the cost and the risks among a group of firms. Hossain and Kauranen (2016) suggested that the size of network plays a vital role in the performance improvement of the participating firms. When the network increases, the risk decreases, and SMEs can become more innovative with less cost and less risk. However, as the network size increases more, the 
cost of coordination increases in such a way that it can overshadow the gain of the cooperation.

Kamalian, Rashki, Hemmat, and Jolfaie (2015) found that SMEs can use formal and informal cooperation networks to exchange resources or knowledge with several entities like governmental bodies, research institutes, universities, customers, suppliers, LEs and other SMEs. Salisu and Abu Bakar (2018b) argued that technological collaboration can boost the product innovation and the technological capability of SMEs. Along the same line, Noni, Orsi, and Belussi (2018) suggested that the European Commissions should implement policies that encourage cooperation between SMEs in knowledge-intensive regions and SMEs in lagging-behind regions. Likewise, Bylok, Pabian, and Kuceba (2016) opined that the readiness of SMEs and the existence of the supportive governmental policies could support the creation of cooperation networks among SMEs. Birgit, Mike, and Chung-Shing (2018) argued that although SME managers realize the importance of cooperation, the lack of willingness and the absence of trust can limit the potential of innovation through cooperation. Likewise, Hossain (2015) stated that the corporate culture has a significant impact on the successful implementation of open innovation and collaboration. Cooperation networks can empower SMEs to overcome their resource limitations through resource sharing. Government policies should encourage SMEs to participate in cooperation networks. Two particular examples that demonstrated how successful cooperation networks could empower SMEs to innovate even with limited resources are the German Mittelstand firms and the Kyoto prototyping network. 
The German Mittelstand firms are SMEs that managed to become highly innovative despite the severe limitations in the human and financial resources compared to LEs (Massis, Audretsch, Uhlaner, \& Kammerlander, 2018). These firms share some common characteristics that enable them to innovate and compete. Uwajumogu, Nwokoye, Anochiwa, and Ojike (2015) listed several typical characteristics of the German Mittelstand firms such as global reach, high technological production, and single-family ownership. Similarly, Massis et al. (2018) found that the German Mittelstand firms share six traits which are (a) niche focus and customer collaboration, (b) globalization strategy, (c) preference for self-financing, (d) long run mindset, (e) superior employee relations, and (f) strong community relations. The innovative drive and the strong networking are the bases of the competitive edge of the German Mittelstand firms (Uwajumogu et al., 2015). Collaboration with customers in one of the makers of cooperative networks. The single-family ownership allows for long-term planning as well as building trust with the local community based on stability and historical relations (Massis et al., 2018). The characteristics of the German Mittelstand firms form a good foundation for SMEs to follow and innovate with scarce resources. The way the Mittelstand firms build their networks sets an example for other SMEs with similar structures and ownership.

The Kyoto prototyping network is a cluster of companies that implement a collective innovative strategy to take on projects that other companies turn down (Mizuno, 2014). Prototyping projects sometimes appear to be difficult because of the absence of a reliable cost estimation or an incomplete requirement list. SMEs are 
hesitant to accept such project because of the high uncertainty and the associated risk. The Kyoto prototyping network creates a virtuous circle whereby SMEs get the opportunity to participate in the cutting-edge research projects by investing $5 \%$ of their profits (Mizuno, 2014). The knowledge that SMEs gain through this participation builds the internal knowledge of the firm that can facilitate the winning of new orders. Through this collective strategy, SMEs can become highly innovate without fearing the risks of uncertainty.

\section{Transition}

Section 1 included the foundation of this study. I introduced the background of the problem, the problem statement, the purpose statement, the research question, the conceptual framework, and a critical review of the relevant literature. In section 2, I presented the role of the researcher, the participants, the research method, the research design, and population and sampling. Additionally, Section 2 contains data collection, data organization, data analysis, and a discussion about the reliability and validity of the study. Section 3 contains a presentation of the findings. I described how these findings could contribute to professional practice and positive social change. Moreover, I provided recommendations for action and suggestions for future research. 
Section 2: The Project

SMEs represent the engine of economic development in many countries. SME managers can improve the performance of their firms through the implementation of innovation. Exploring successful strategies for innovation implementation in SMEs was the primary objective of this study. This section includes a description of the research design, including participants, sampling method, data collection, data organization, and data analysis. Furthermore, this section covers the role of the researcher, research ethics, and research rigor.

\section{Purpose Statement}

The purpose of this qualitative multiple case study was to explore strategies that some SME managers use to implement innovation in their organizations to meet performance goals. The target population was five managers from four SMEs in Dubai, who have successfully implemented innovation in their organizations to meet performance goals. The implication for positive social change includes the potential to create employment opportunities and reduce poverty in developing countries through economic development.

\section{Role of the Researcher}

The researcher is the instrument for data collection in qualitative research (Bahrami, Soleimani, Yaghoobzadeh, \& Ranjbar, 2016). Being the only researcher in this study, I was responsible for selecting participants, preparing interview questions, conducting interviews, analyzing the data, and drawing the conclusions along with recommendations. Although I have been living in Dubai since 1998, I did not have any 
direct interaction with any of the participants or their organizations. Furthermore, throughout my professional career, I have worked for two mobile service provider companies, which were both LEs.

The National Commission for the Protection of Human Subjects of Biomedical and Behavioral Research (1979) published the Belmont Report which contains ethical principles for research including human participants. Doody and Noonan (2016) stressed that voluntary and informed participant consent is a fundamental requirement of ethical research. Before conducting interviews to collect data, I obtained the participants' signature on the informed consent form. Through this form, I explained the participants' rights to accept, reject, or withdraw at any time during the study without any consequences. Yin (2017) stressed that it is mandatory to refer to the Institutional Review Board (IRB) for approval and guidance before moving forward with a case study that involves human participants. Therefore, I did not start recruiting participants before obtaining Walden University IRB Approval. I conducted this study under Walden University IRB approval number 06-26-18-0387957. This approval expires on June 25, 2019.

Researchers making case studies should have a good understanding of the subject before conducting the research, which makes them vulnerable to bias because of preconceptions (Yin, 2017). Researcher bias in the form of preconceptions can cause selective observation, selective recording of information, and biased data interpretation (Cypress, 2017). To mitigate bias, researchers should be aware of their preconceptions (Yin, 2017). Likewise, Cypress (2017) suggested that researchers should practice critical 
self-reflection about their preconceptions that may taint their conclusions. In addition, Darawsheh (2014) postulated that reflexivity could improve the rigor of qualitative research by reducing the researcher bias and increasing the researcher's subjectivity. Therefore, I mitigated potential bias by maintaining awareness of my preconceptions, being open to evidence against my preconceptions, and using other sources of data to validate the analysis and conclusions. I maintained a journal to record my feelings and thoughts during the interviews. Marshall and Rossman (2016) compiled a list of strategies that researchers can follow to avoid bias in interpretation. One of these strategies involves member checking (Marshall \& Rossman, 2016). Member checking means sharing the initial analysis with the participants for verification (Birt, Scott, Cavers, Campbell, \& Walter, 2016: Grossoehme, 2014; Guba, 1981; Harvey, 2015). I shared my initial analysis with the participant to make sure that I captured what each participant wanted to say. Another strategy involves the purposeful examination of different interpretations of the data (Marshall \& Rossman, 2016). By addressing other interpretations of the data, I mitigated personal bias, and I demonstrated a more subjective analysis.

Castillo-Montoya (2016) proposed that qualitative researchers use interview protocols to improve the quality of the data that they collect through interviews. Moreover, Bernard (2013) listed several advantages of using an interview protocol, such as (a) efficient use of time with busy participants, (b) showing the participant that you know what you want, (c) demonstrating flexibility through open-ended and probe questions, and (d) covering the same ground with each of the participants. Arsel (2017) 
advised researchers to develop their interview protocols to remain focused during the interview. I constructed and used an interview protocol that consisted of (a) a script for the beginning, (b) a script for the end, and (c) reminders to watch body language, take notes, ask probing questions, be a good listener, and maintain eye contact (Appendix A).

\section{Participants}

The eligible participants were SME managers who have successfully implemented innovations in their organizations to improve performance. In this study, I limited the scope to four SMEs operating in Dubai and used purposive sampling to select suitable participants working in the four SMEs. Purposive sampling provides the researcher with data from knowledgeable participants who have good experience with the subject of the study (Wagstaff \& Williams, 2014). To find SME managers who have implemented innovation, I contacted the director of each of the four SMEs and asked for suitable candidates that met this criterion. I contacted the four directors, introduced myself, explained the purpose of the study, and asked for candidates who could participate in the study. Getting nominations from SME directors increased the chances that the candidates would have the required experience about innovation implementation that aligned with the overarching research question.

Researchers should work on establishing a good working relationship with the participants to obtain high-quality data. Marshall and Rossman (2016) argued that a major part of the success of qualitative interviews hinges on the interpersonal skills of the researcher. Major success factors in the relationship between the researcher and the participants include building trust, sensitively considering ethical issues, and being aware 
of the politics of organizations (Marshall \& Rossman, 2016). I initiated this relationship through phone calls and emails to explain to the potential participants that the purpose of the research would be to explore successful strategies for innovation implementation in SMEs. I made sure that the participants understood that their contribution would be to speak about their personal experience regarding the successful implementation of innovation in SMEs.

\section{Research Method and Design}

\section{Research Method}

I used a qualitative methodology for this study. Researchers use qualitative research methods to explore the perceptions and experiences of individuals (Corbin \& Strauss, 2014). Qualitative methods are suitable for exploratory or descriptive studies that aim to uncover tacit knowledge (Marshall \& Rossman, 2016). In addition, Yin (2017) argued that qualitative research methods can allow researchers to obtain an indepth understanding and rich contextual description information about the research question. McCusker and Gunaydin (2015) suggested that researchers use quantitative methods at later stages of the study when the researcher comes to exactly know what he or she is looking for and wants to quantify specific variables in a statistical form. Considering the lack of information about innovation of SMEs in developing countries in general (Xie et al., 2013) and the limited information about the business behavior of SMEs in Dubai in particular (Al-Ansari et al., 2013), qualitative research was more suitable than quantitative research for this study. 
Besides qualitative methods, I considered quantitative and mixed methods. McManamny, Sheen, Boyd, and Jennings (2015) mentioned that quantitative research is useful when testing the hypothesis using quantifiable variables. Park and Park (2016) argued that qualitative research is suitable for exploring or generating a hypothesis about a phenomenon while quantitative research is suitable for testing a hypothesis or a relation between variables. Since the aim of this study was to explore SME managers' strategies to implement innovation and since there was no intent to compare variables nor test a hypothesis, quantitative methods was not suitable for this study. Mixed methods use a combination of qualitative and quantitative methods. The quantitative component of mixed methods would not adde value in the exploratory stage of the research question. Therefore, mixed methods was not suitable for this study.

\section{Research Design}

I used a multiple case study design to conduct this research. The case study design is suitable for collecting rich data using how and why questions about a current phenomenon on which the researcher has no control (Yin, 2017). In addition, Yin (2017) viewed the multiple case study design as a replication of a single case study in two or more cases. He argued that the multiple case study design is better than the single case study design, as multiple case study design provides stronger findings that are less likely to be resulting from repeating unique conditions.

Researchers use phenomenological research design to gain an accurate understanding of the essence of a lived experience in the words of those who went through it (Moustakas, 1994). The phenomenological research design was not suitable 
for this study. Ethnography addresses customs, beliefs, and behaviors of a specific cultural group (Percy et al., 2015). The focus of ethnography did not apply to my study and therefore was not suitable design for this study. Narrative inquiry is an in-depth interview where the researcher collects life stories of the participant (Marshall \& Rossman, 2016). Since the life stories did not contribute to the subject of this study, a narrative inquiry was not a suitable design for this study.

Data saturation (i.e., informational redundancy) occurs when the researcher no longer hears or sees new information (E1 Hussein, Jakubec, \& Osuji, 2015). Furthermore, El Hussein et al. (2015) argued that data saturation is one of the elements of qualitative research rigor. Data saturation enhances the credibility of qualitative research (Houghton, Casey, Shaw, \& Murphy, 2013). To reach saturation, interviews should continue with new participants until no new information emerges (Gibbins, Bhatia, Forbes, \& Reid, 2014). Therefore, I conducted interviews until new information ceased to emerge.

\section{Population and Sampling}

I used face-to-face interviews to collect data. Interviewees were the primary source of data for this study. Well-informed participants with the right knowledge can add critical data to the study (Yin, 2017). Contrary to quantitative research, where a researcher chooses random sampling to get reliable inferential results, qualitative researchers use a non-probabilistic approach to choose the samples. Applying the same logic of quantitative research sampling on qualitative case study research can lead to misleading results (Yin, 2017). 
In this study, I used purposeful nonrandom sampling to choose the participants. Robinson (2014) referred to purposive sampling strategies as a nonrandom selection of participants to make them a part of the final sample based on their unique knowledge about the research topic. Purposive sampling provides the researcher with data from knowledgeable participants who have good experience with the subject of the study (Wagstaff \& Williams, 2014). Choosing SME managers who have implemented innovation successfully in their organizations was the utilization of purposeful nonrandom sampling.

The number of participants in qualitative research differs from one case to another. Ando, Cousins, and Young (2014) defined data saturation as a moment in research when exploring a problem under study offers no additional themes. Gibbins et al. (2014) suggested that interviews should continue with new participants until no new information emerges. I reached data saturation after interviewing five managers from four different SMEs.

Although an exact number of the participants is difficult to determine before conducting the research, an initial range is necessary to allow for research planning (Robinson, 2014). For instance, Marshall, Cardon, Poddar, and Fontenot (2013) examined 83 qualitative studies and found that the minimum number of cases in multiple case studies was two while the median was five. The minimum number of interviews was ten while the median was 39 (Marshall et al., 2013). I reached data saturation after interviewing five managers from four different SMEs. Data saturation occurs when 
exploring a problem under study offers no additional themes (Ando et al., 2014; El Hussein et al., 2015).

The specific population consisted of managers from four SMEs in Dubai who successfully implement innovation in their organizations. I reached data saturation after interviewing five managers from four different SMEs. Leedy and Ormrod (2015) argued that an interview should take place in a quiet location free of interruption or distraction. Low noise places can serve the purpose of low distraction and are suitable for audio recording. Mitropolitski (2015) asked the participants to choose the location and the time of the interviews. Arsel (2017) suggested that researchers should establish a good rapport before starting the interview questions. A good rapport reduces the participant's discomfort which can provide better answers to the interview questions. I conducted the interviews in a place that was suitable for each interviewee as each interviewee had different preferences as to the time and place for conducting the interview. I was flexible to ensure that interviewees were comfortable and relaxed.

\section{Ethical Research}

Doody and Noonan (2016) stressed that voluntary and informed participant consent is a fundamental requirement of ethical research. Before conducting interviews to collect data, I obtained the participants' signature on the informed consent. Through the informed consent process, I explained to participants their right to either accept or reject taking part in the study. Participants had the right to withdraw at any time during the study without any consequences. I did not offer any incentives for the participants in this study. 
Ethical committees for research involving humans focus primarily on minimizing harm, informed consent, privacy, and confidentiality (Kendall \& Halliday, 2014). Before submitting the proposal for this study, I completed the Protecting Human Research Participants (PHRP) course through the National Institutes of Health (NIH). Yin (2017) stressed that it is mandatory to refer to the IRB for approval and guidance before moving forward with a case study. Before proceeding with data collection, I obtained Walden University IRB approval. I conducted this study under Walden University IRB approval number 06-26-18-0387957 which expires on June 25, 2019. The informed consent form contains additional details about privacy and confidentiality to assure participants that their identity and their companies' identity would remain confidential. I did not include any information in the study that could identify participants or their organizations. To ensure confidentiality, I referred to each participant using a unique alphanumeric symbol. All physical and soft records of the collected data will be locked in a safe place for 5 years where the soft records are password protected for increased security. After 5 years, I will destroy all the physical and soft records.

\section{Data Collection Instruments}

The researcher is the instrument for data collection in qualitative research (Bahrami et al., 2016; Denzin \& Lincoln, 2013). In addition, Castillo-Montoya (2016) argued that the researcher is the most useful instrument in qualitative research because the researcher can adapt the interview through careful listening to the participant. The sensitivity, responsiveness, and flexibility of the researcher are what makes humans the most suitable research instruments in qualitative research. Nevertheless, since the 
researcher is the primary data collection instrument in qualitative research, the researcher should be vigilant to the possible moderation of data by the collection instrument. Researcher biases and preconceptions can distort the collected data. Researchers should work on mitigating the researcher biases. In a qualitative case study, the researcher should use at least two sources of data collection to enhance the data credibility (Yin, 2017). Therefore, I collected data from two different sources. The primary source was the semistructured interviews with SME managers from four SMEs who have implemented innovation in their organizations. The secondary source was the SMEs' internal documents, SMEs' websites, review websites, and press releases.

Onwuegbuzie and Byers (2014) posited that interviews are one of the most effective and most common approaches for data collection in qualitative research. Ajayi and Morton (2015) used semistructured interviews to obtain an in-depth understanding of the participants' views on the marketing innovations within their organizations. At the same time, Castillo-Montoya (2016) proposed that qualitative researchers use interview protocols to improve the quality of the data that they collect through interviews. Arsel (2017) advised researchers to develop their interview protocols to remain focused during the interview. Therefore, I constructed an interview protocol to guide the interviews in this study (Appendix A). Each interview consisted of seven main questions (Appendix A) with follow-up questions after each main question. To improve credibility, Guba (1981) suggested using member checking. Grossoehme (2014) proposed that a researcher share the analysis with some or all the participants to get their feedback. Likewise, Harvey (2015) opined that sharing the analysis with the participants reduces 
researcher bias and ensures that the voices of the participants are the basis of the data analysis rather than the researcher preconceptions. As part of the interview protocol (Appendix A), I shared my initial analysis with the participants for verification.

The second sources of data were the SMEs' internal documents, SMEs' websites, review websites, and press releases. I used the secondary data to improve validity through methodological triangulation. Yin (2017) mentioned six different sources of data: (a) documentation, (b) archival records, (c) interviews, (d) direct observations, (e) participant observation, and (f) physical artifacts. These sources are complementary, as each source has its unique strengths and weaknesses (Yin, 2017). To improve the validity of the study, Leedy and Ormrod (2015) suggested using triangulation by incorporating more than one source of data. In addition, Guba (1981) argued that triangulation could improve research credibility. The secondary source of data included the SMEs' internal documents, SMEs' websites, review websites, and press releases.

\section{Data Collection Technique}

The overarching question that guided this study was: What strategies do SME managers use to implement innovation in their organizations? To answer this question, I conducted a multiple case study research using semistructured interviews for data collection. In addition, I used the companies' internal documents, SMEs' websites, review websites, and press releases to improve the reliability of the primary data through methodological triangulation. Guba (1981) opined that triangulation could improve research credibility. 
Onwuegbuzie and Byers (2014) posited that interviews are one of the most effective and most common approaches for data collection in qualitative research. McIntosh and Morse (2015) opined that face-to-face interviews have the advantage of providing rich data through verbal and nonverbal communication. Semistructured interviews provide the opportunity for consistent data collection while allowing the flexibility for elaboration on any of the main questions. Ajayi and Morton (2015) used semistructured interviews to obtain an in-depth understanding of the participants' views on the marketing innovations within their organizations. On the other hand, face-to-face interviews maximize the influence of the interviewer (Bernard, 2013; McIntosh \& Morse, 2015). During face-to-face interviews, an interviewer needs to be skilled enough to be able to ask questions without implying to the participant what he or she should answer (Bernard, 2013). I used a notebook to write down my thoughts during the interview and to keep myself aware of my emotions and preconceptions. Furthermore, I avoided leading questions to reduce my influence on the participants' answers.

Castillo-Montoya (2016) proposed that qualitative researchers use interview protocols to improve the quality of the data that they collect through interviews. I developed my interview protocol which consisted of (a) a script for the beginning; (b) a script for the end; and (c) reminders to watch body language, take notes, ask probing questions, be a good listener, and maintain eye contact (Appendix A). Each interview consisted of seven main questions (Appendix A). The duration of each interview was between 31 minutes and 43 minutes. Interviews took place at a suitable time and location for each participant. I audio recorded four out of five interviews after getting the 
participants consent. The interview questions contributed knowledge towards answering the overarching research questions. Each question extracted information about the successful implementation strategies of innovation in SMEs.

The use of semistructured interviews for the collection of primary data has advantages and disadvantages. Face-to-face interviews are one of the most effective approaches for data collection in qualitative research (Onwuegbuzie \& Byers, 2014). Semistructured interviews are suitable to attain an in-depth understanding of the participants' views about the topic under study (Ajayi \& Morton, 2015). Despite being an effective tool for in-depth data collection, using interviews poses challenges that researchers have to deal with. One of these challenges is the researcher bias in the form of selective observation, selective recording of information, and biased data interpretation (Cypress, 2017). Another disadvantage of interviews is that data collection and interpretation is complex and time-consuming. Sutton and Austin (2015) estimated that 45 minutes of audio-recorded interview will need 8 hours to transcribe and will generate more than 20 pages of transcribed dialogue. Regardless of these disadvantages, face-toface interviews remain one of the most common approaches of data collection in qualitative research. Researchers use the CAQDAS to manage and analyze more data in less time using less effort.

The use of archival records as a secondary source of data has advantages and disadvantages. The use of a second source of data can allow researchers to use triangulation to improve the validity of the study (Fusch \& Ness, 2015; Leedy \& Ormrod, 2015). The advantage of getting access to a second source of data to validate the primary 
data does not come without cost. Reviewing additional data such as archival records can be a time-consuming process (Yin, 2017). The records that a researcher can have access to may be outdated, incomplete, or irrelevant. The time the researcher spends on archival records may or may not result in a significant addition to the primary data.

I used Nuance Dragon for automatic transcription from audio to text to transcribe the interview recordings. I transcribed all the interviews myself to guarantee privacy and confidentiality. Sutton and Austin (2015) estimated that 45 minutes of audio-recorded interview will need 8 hours to transcribe and will generate more than 20 pages of transcribed dialogue. After concluding the data analysis, I shared the initial analysis with the participants to perform member checking. Birt et al. (2016) suggested that a researcher shares the analysis with some or all the participants to get their feedback.

\section{Data Organization Technique}

The organization of research data is one of the unique challenges of qualitative research. During qualitative research, researchers use CAQDAS to manage the overwhelming research data (Houghton, Murphy, Shaw, \& Casey, 2015). Researchers have been increasingly using CAQDAS since the first generation of tools appeared in the 1980s (Woods, Paulus, Atkins, \& Macklin, 2016). To improve research reliability, Yin (2017) proposed the use of case study protocol and the development of case study database. In addition, Yin (2017) suggested that researchers use a computer-assisted qualitative data analysis software (CAQDAS) or a word processing tool to arrange the interviews results. Antoniadou (2017) listed a number of software packages for qualitative data analysis such as Transana, Atlas.ti, and NVivo. I transcribed the 
interview recordings to ensure confidentiality of the data. I used Microsoft Word and Microsoft Excel for data storing, data coding, theme finding, and organizing the interview comments in tabular forms.

Bernard (2013) mentioned four types of field notes that a qualitative researcher must take. The contents of these notes are either personal feelings or a list of research steps and decisions in chronological order. I had a research log that contained all the research steps and decisions. A research log would be useful in case of an audit or any future data reanalysis. I had a reflective journal that contained my feelings and perceptions during the research. The reflective journal was useful in bracketing my emotions to reduce researcher bias. To ensure confidentiality, I referred to each participant using a unique alphanumeric symbol. I used P1C1 to identify the first participant of the first SME. Similarly, PxCy referred to participant x from company y. I will keep all the research data (i.e., audio recordings, interview transcripts, interview comments, consent forms, invitation letters, flash disk, and all the relevant documents and files) in a safe place for 5 years. At the end of the 5 years, I will destroy all the records and documents.

\section{Data Analysis}

Yin (2017) opined that a case study design offers the opportunity to collect data from multiple sources. I collected data from two sources. The primary source was from the semistructured interviews with managers from four SMEs who have implemented innovation in their organizations. The secondary source was the SMEs' internal documents, SMEs' websites, review websites, and press releases. Denzin (1989) 
described methodological triangulation in which a researcher uses more than one approach for data collection using the same research design as within-method. Marshall and Rossman (2016) opined that triangulation involves the collection of data that is relevant to the research problem from more than one source. Likewise, Hadi and Closs (2016) described triangulation as the search for information about a specific phenomenon from multiple sources or using different data gathering methods. Triangulation contributes to improving the validity of qualitative analysis (Fusch \& Ness, 2015; Leedy \& Ormrod, 2015). Similarly, Guba (1981) opined that triangulation could improve research credibility. Denzin (1989) described a methodological triangulation in which a researcher uses more than one approach for data collection using the same research design as within-method triangulation. I used the within-method triangulation when analyzing the interview data and the archival records.

Bernard (2013) described data analysis as the search for patterns in data and for ideas to explain the reasons behind these patterns. Yin (2016) proposed the following five-phase approach for qualitative data analysis: (a) compile, (b) disassemble, (c) reassemble, (d) interpret, and (e) conclude. Yin stressed that this approach is cyclic but not necessarily linear. He mentioned that the researcher could move back and forth between two phases. For example, the researcher can go back and disassemble or reassemble the data in a different way after performing data interpretation. Yin described this process as both recursive and iterative. I followed Yin's five-step process for data analysis. 
Compile. Data compilation involves arranging all the research data into a particular order to create a database (Yin, 2016). I transcribed the interviews myself to guarantee privacy and confidentiality. Sutton and Austin (2015) estimated that a researcher would need around 8 hours to transcribe an audio-recorded interview of 45 minutes which will generate more than 20 pages of transcribed dialogue. After transcribing the interviews, I used Microsoft Word to code the data and used Microsoft Excel group the codes into themes. Throughout this research project, I used a password to protect the participants' data.

Disassemble. Disassembling is a trial-and-error process that involves dividing the data into fragments (Yin, 2016). I divided the interview transcripts into pieces of information and assigned a unique code for each piece of information. Each code represented a core topic of each category of data. Coding included the identification of similar and different topics from the narratives of the participants (Sutton \& Austin, 2015).

Resassemble. Reassembling includes the rearrangement of the coded data into different groupings using graphical or tabular forms (Yin, 2016). I rearranged the codes and observed the emerging themes or patterns. This was a critical step in the data analysis process. Elo et al. (2014) and Yazan (2015) opined that the analysis of qualitative case studies depends on the knowledge and experience of the researcher in identifying significant patterns in the collected data.

Interpret. Data interpretation includes the utilization of the reassembled data to create a new description that will become a central element in the final results (Yin, 
2016). The researcher's capacity to understand and explore the collected data is critical for creating a meaningful interpretation (Finfgeld-Connett, 2014). I interpreted the data by trying to create a new narrative that describes the collected data. Yin (2016) described a good interpretation as being complete, fair, credible, accurate, and new. I tried to get as close as possible to providing a good interpretation. After making the initial interpretation I evaluated the result using Yin's criteria for a good interpretation.

Conclude. As part of the conclusion, the researcher formulates key statements about the findings of a study based on the interpretation of the reassembled codes and the emerging themes (Yin, 2016). I stated my conclusions based on my interpretation of the codes and the resulting themes. I tried to answer the research question. As part of the conclusion, I provided a call for future research to cover the gaps that were uncovered by this study.

Yin (2017) suggested that researchers use computer-assisted qualitative data analysis software (CAQDAS) or a word-processing tool to organize the research data collected from multiple sources. Antoniadou (2017) listed a number of software packages for qualitative data analysis such as Transana, Atlas.ti, and NVivo. Although a CAQDAS can save time and effort, the researcher still has to make all the decisions related to the data analysis (Yin, 2016). I used Microsoft Word and Microsoft Excel during this study to assist me in all the various phases of data analysis including data storing, data coding, and theme finding.

Sutton and Austin (2015) described in depth the practical issues related to data collection, analysis, and management. The steps involved in qualitative data analysis are: 
(a) transcribing the data, (b) coding the data, and (c) creating themes (Sutton \& Austin, 2015). I went through the interview scripts and highlighted sentences or group of sentences in different colors. I copied all the highlighted parts into Microsoft Excel and started the coding. The total number of coded phrased were 288 and the resulting unique codes were 43. I grouped the unique codes into five themes. Finally, I examined the resultant themes against the conceptual framework to check for agreement or disagreement. Furthermore, I compared the resultant themes with the outcomes of recent, similar studies.

\section{Reliability and Validity}

The diversity of types of qualitative research has made it difficult to create consensus around the proper approach for judging the quality and rigor of any study (Leung, 2015). The most common criteria for assessing the quality of a qualitative research are the research methodology and the data interpretation (Leung, 2015). A good qualitative research study should be systematic and transparent throughout all phases of the study (Yin, 2017). In addition, Guba (1981) suggested the following four criteria for judging the rigor of qualitative research: credibility, transferability, dependability, and confirmability. Guba's criteria are widely accepted as an approach to assess the quality of qualitative research (Houghton et al., 2013; Leung, 2015). I used Guba's criteria to demonstrate the validity and the reliability of this study.

\section{Reliability}

Reliability is the possibility of reaching the same conclusions when a researcher repeats a case study following the same procedure of the initial study (Yin, 2017). 
Similarly, Leung (2015) opined that a reliable qualitative study should be replicable. Guba (1981) used the term dependability to refer to the reliability of qualitative research. Yin (2017) proposed the use of a case study protocol and the development of a case study database to improve reliability. Castillo-Montoya (2016) proposed that qualitative researchers use interview protocols to improve the quality of the data that they collect through interviews. Morse (2015) mentioned three techniques to improve reliability: triangulation, external auditing, and member checking.

My strategy to improve the reliability of this study consisted of several actions.

First, I recorded the details of conducting this study to enable other researchers to repeat it and reach similar conclusions. I kept a trail of all the decisions I made throughout this

study. Second, I used methodological triangulation to analyze the interview data and the archival records of the SMEs. Third, I shared my analysis with the participants to get their feedback and to ensure that I captured what each participant wanted to say.

\section{Validity}

Leung (2015) referred to qualitative research validity as the suitability of the research tools, processes, and data to the research question. Yin (2017) mentioned three types of validity: internal validity, external validity, and construct validity. Guba (1981) and Yin (2017) described internal validity as the accuracy or truthfulness of the research findings and external validity as the generalizability of the findings. Yin (2017) explained construct validity as the opposite of subjectivity. Guba (1981) used the terms credibility, transferability, and confirmability to refer to internal validity, external validity, and objectivity, respectively. 
Triangulation and member checking are two techniques that can improve research credibility (Guba, 1981). To that end, Fusch and Ness (2015) stressed that addressing the impact of researcher's personal views is a fundamental component of the qualitative study. Furthermore, getting to know the perspectives of the participants may be one of the most challenging problems that can face the researcher (Fusch \& Ness, 2015). The primary source of data was from face-to-face interviews. I shared my initial analysis with the participants to ensure the accuracy of the interview data. To improve credibility, I used data from the SMEs' internal documents, SMEs' websites, review websites, and press releases as a secondary data source. I looked for convergence between the primary and the secondary data sources to ensure the consistency of the findings.

A detailed description of the data collection process can facilitate transferability (Yin 2014). Similarly, Guba (1981) stressed that the role of the research in transferability is limited to providing a detailed account, or a thick description, of the context of the study. To judge the possibility of transferring the findings from one study to another, the reader should have a thick description of both studies. It is up to the reader to decide whether the findings from one study apply to another study based on the similarities between the two (Guba, 1981). I provided a detailed description of the context of the case study to allow readers to make informed decisions about the suitability of applying the findings to other cases.

Houghton et al. (2013) suggested using an audit trail and reflexivity to improve confirmability. In addition, Guba (1981) proposed the use of triangulation as a strategy to reduce researcher bias and improve confirmability. Furthermore, Fusch and Ness 
(2015) opined that triangulation could improve the validity of the study results. I had a reflective journal to record my feelings and perceptions during the research. Moreover, I used methodological triangulation to improve confirmability.

El Hussein et al. (2015) argued that data saturation enhances the credibility and rigor of qualitative research. Data saturation occurs when exploring a problem under study offers no additional themes (Ando et al., 2014; El Hussein et al., 2015). Similarly, Gibbins et al. (2014) suggested that interviews should continue with new participants until no new information emerges. I reached data saturation after interviewing five managers from four different SMEs.

\section{Transition and Summary}

Section 2 included the role of the researcher, the participants, the research method, the research design, population and sampling. Additionally, I presented data collection, data organization, data analysis, and a discussion about the study reliability and validity. Section 3 contains a presentation of the findings. I described how these findings can contribute to professional practice and positive social change. Furthermore, I provided recommendations for action and suggestions for future research. 
Section 3: Application to Professional Practice and Implications for Change

Introduction

The purpose of this qualitative multiple case study was to explore strategies that some SME managers use to implement innovation in their organizations to meet performance goals. I collected the data from four SMEs operating in Dubai. The primary data came from five semistructured interviews while the secondary data came from the SMEs' internal documents, SMEs' websites, review websites, and press releases. The analysis of the primary and secondary data revealed five main themes about the strategies that SME managers use to implement innovation to meet performance goals. The five themes are: the role of innovation in competition and survival; ideas are the starting points for innovation; the role of the top management in cultivating an innovative culture; idea testing, evaluation, and seeking honest feedback; and the customer as a resource for the company. This section contains details about the research findings represented through the five themes, the application of the findings to professional practice, the implications for social change, and recommendations for action. I closed this section with recommendations for future research and a concluding statement about the most prominent outcomes.

\section{Presentation of the Findings}

The central question of this study was: What strategies do SME managers use to implement innovation in their organizations to meet performance goals? I collected the primary and the secondary data from four SMEs operating in Dubai. I conducted semistructured interviews with five SME managers working for the four SMEs. Each 
interview lasted between 31 minutes and 43 minutes. I audio recorded four out of the five interviews. Based on the request of one participant, one interview was not recorded, and I had to take notes instead. After transcribing the interviews, I performed member checking by sharing my initial analysis with each of the five participants. During the data analysis, I transcribed and coded the text from the interviews.

I triangulated the primary data from the interviews with the secondary data from the archival records. The archival records included the SMEs' internal documents, SMEs' websites, review websites, and press releases. I used these records to triangulate the secondary data with the primary data in several ways. Firstly, I used an internal card from company $\mathrm{C} 1$ to confirm that the company goals are communicated clearly to all employees. Secondly, I used LinkedIn to establish the diversity of the employees in company C4. The company $\mathrm{C} 4$ had ten employees who came from seven different countries. Thirdly, I used a review site for smartphone applications to see how Participants $\mathrm{P} 1 \mathrm{C} 3$ and $\mathrm{P} 2 \mathrm{C} 3$ used review comments to update their product. In fact, the company $\mathrm{C} 3$ issued 11 release upgrades in eight months which is at a rate of one release upgrade every 21 days. Through these release upgrades, the company $\mathrm{C} 1$ added 11 new features to their smartphone application. Finally, I used Zamato to check the reviews of company $\mathrm{C} 2$ and found that over 500 customers gave this company 4.1 out of 5 .

With each interview, the number of new codes decreased. From the first interview, I got 21 new codes. When I reached the fourth interview, I got one new code. I stopped doing the interviews after the fifth interview because I reached data saturation. The information became repetitive and I stopped getting new information (Table 1). The 
following themes emerged from the analysis of the primary and secondary data: the role of innovation in competition and survival; ideas are the starting points for innovation; the role of the top management in cultivating an innovative culture; idea testing, evaluation, and seeking an honest feedback; and the customer as a resource for the company.

\section{Table 1}

Number of Codes per Interview

\begin{tabular}{llll}
\hline Interview & Participant & Number of Unique Codes & Number of New Codes \\
\hline 1 & P1C1 & 20 & 20 \\
2 & P1C2 & 21 & 14 \\
3 & P1C3 & 21 & 6 \\
4 & P1C4 & 21 & 1 \\
5 & P2C3 & 21 & 0 \\
\hline
\end{tabular}

\section{Theme 1: The Role of Innovation in Competition and Survival}

Innovation is a significant element for SME survival and growth (Farsi \& Toghraee, 2014). Participant P1C1 said that innovation is what makes the company compete. Participant P1C2 mentioned that you have to be different to succeed. Participant P1C4 mentioned that we innovate to distinguish our self and to capture opportunities. Participant P1C3 said that we compete for the future. Participant P2C3 mentioned that without innovation you cannot survive especially when you are a technology company who needs to follow the advancement of technology faster that 
other companies. This theme appeared 44 times in the interview transcripts, which represented $15 \%$ of all the codes (Table 2 ).

Table 2

Frequency of Main Theme One

\begin{tabular}{lll}
\hline Theme & Number of & Percentage of \\
& Occurrences & Occurrence \\
\hline The Role of Innovation in Competition and & 44 & $15 \%$ \\
Survival & & \\
\end{tabular}

Similarly, Asare (2014) argued that SME managers could increase the competitiveness of their SMEs by incorporating innovation into their organization. Furthermore, Hajar (2015) noted that innovation has a positive influence on the performance of the company. Boachie-Mensah and Acquah (2015) considered innovation to be a corporate strategy that can lead to a competitive edge through producing better products, improving the market performance, and building a good reputation. Participant P1C3 said that we compete for the future. Participant P1C3 added that to survive in the technology market, innovation should be at the core of the organization DNA because technology changes fast.

Innovation acts as a mediator between resources and performance (De Zubielqui et al., 2014; Tamayo et al., 2015). Participant P1C1 used innovation to automate the existing processes, to improve the speed of ordering and replying, and to acquire a competitive advantage by differentiating the company from other similar companies. 
Automating an existing process can save paper for the company, save time for employees and customers, save effort for the employees, and improve the customer experience. Participant P1C2 used innovation to increase the cooking speed, to differentiate the company $\mathrm{C} 2$ from other companies, and to turn disadvantages into advantages.

Participant P1C2 said that to improve the cooking speed, the cooking process should be divided into smaller steps and then decide on the steps that can be done in parallel or prepared beforehand. Participant P1C3 used innovation to reduce cost and to compete for the future. Participant P1C3 mentioned that technology companies should never be late in adapting to the market trends. Each participant used innovation in a different way and for a different reason. Some of the drivers for innovation were to reduce cost, improve efficiency, gain a competitive advantage, and have a differentiating factor. All these drivers can contribute towards better performance.

The role of innovation in competition aligns with the RBV theory. Innovation is one of the resources that are rare (R), inimitable (I), and non-substitutable $(\mathrm{N})$. Barney (1991) argued that competitive advantage comes from implementing a unique valuecreating strategy while sustained competitive advantage comes from implementing a unique value-creating strategy that other firms cannot duplicate (Barney, 1991). Baumane-Vitolina and Cals (2013) opined that the ability to produce innovations falls under special competences which are difficult to reproduce by other firms. Narek (2014) opined that many times the innovation activities of SMEs are inefficient. Dubai SME (2014) mentioned that only $13 \%$ of SMEs implement. Therefore, innovation is a rare (R) resource that few SMEs have. Resources that are difficult to reproduce by other firms are 
rare $(\mathrm{R})$, inimitable $(\mathrm{I})$, and non-substitutable $(\mathrm{N})$. Barney (1991) argued that firms could achieve and sustain their competitive advantage if they possess resources that are valuable, rare, inimitable and non-substitutable (VRIN). If SME managers can utilize innovation (RIN) resources to create value (V) for their companies, then these SME managers can achieve a sustainable competitive advantage. The key role of innovation in SME competition and survival is in line with the RBV theory.

\section{Theme 2: Ideas are the Starting Points for Innovation}

All the participants stressed the importance of a good idea as a starting point for their innovation. Participant P1C3 mentioned that the first important thing about innovation is ideas. Participant P1C2 believed that the initial idea was the reason for the success of the business. Rua and França (2017) described innovation as the encouragement of creativity and new ideas that can result in new processes, services, or products. Similarly, Omerzel and Jurdana (2016) defined the ability to innovate as the successful implementation of new ideas, processes, or products. Ideas are major contributors towards successful innovations. This theme appeared 24 times in the interview transcripts, which represented $8 \%$ of all the codes (Table 3 ).

Table 3

Frequency of Main Theme Two

\begin{tabular}{llc}
\hline Theme & Number of & Percentage of \\
& Occurrences & Occurrence \\
\hline Ideas are the Starting Points for Innovation & 24 & $8 \%$ \\
\hline
\end{tabular}


The process of innovation has several distinct phases. Heikkilä, Bouwman, Heikkilä (2018) opined that any innovation process consists of initiation, ideation, experimentation, and implementation. Similarly, Perry-Smith and Mannucci (2017) argued that the journey of an idea starts with idea generation and ends with idea implementation. Likewise, Grzegorz and Robert (2018) opined that searching for ideas is the first step of the innovation process. Therefore, ideation or idea generation is the first step that comes after initiating the requirement for innovation because of a specific need. However, one cannot achieve innovation without a proper implementation of the ideas. To innovate is to implement a good idea in an efficient way (Halim et al., 2014; Tehseen et al., 2016). A good idea is a necessary condition for innovation, but it is not sufficient. To realize the benefits of innovation, the good idea must be implemented.

Ideas can come from several different sources such as the top management, the employees, and the customer. Participant P1C1 said that their ideas come from the customer needs and the employee needs with the aim of improving the employee working conditions and making the customer experience hassle-free. Benbya and Leidner (2018) mentioned that large companies like IBM, Shell, and Citibank gather innovative ideas from their customers, employees, and business partners. Participant P1C3 stated that he uses meditation to clear his mind and allow ideas to flow. Participant P1C2 mentioned that he gets ideas by looking at a problem in different ways. He added that sometimes using an old idea in a new way is also innovation. Despite the various ways participants use to generate and elicit ideas, all participants agreed on the key role that ideas play in enabling innovation. 
Hargadon and Sutton (2000) considered ideas and the innovation that comes from ideas as the most valuable resources a firm can have. In addition, De Zubielqui et al. (2014) concluded that ideas can have an impact on the performance of the firms when these ideas are mediated by innovation. The consideration of ideas as valuable resources that can improve the performance of a firm is in line with the RBV theory. Since the ideas that produce innovation are valuable resources, they can provide companies with a competitive advantage. Even if other companies try to copy the same ideas, it is the implementation of these ideas through the mediation of innovation which makes the results unique, valuable, and inimitable. Unique and valuable resources provide companies with competitive advantages and the inimitability of resources makes a competitive advantage sustainable. Therefore, a company that generates ideas to fuel innovation will possess a sustainable competitive advantage in line with the RBV theory.

\section{Theme 3: The Role of the Top Management in Cultivating an Innovative Culture}

Around $47 \%$ of the codes I generated from the interview data related to the role of the top management and the corporate culture in fostering innovation. All participants agreed on the key role of the corporate culture in supporting and facilitating the implementation of innovation. Szymańska (2016) argued that the corporate culture is a unique feature of each organization that is influenced mostly by the top management. In addition, Sattayaraksa and Boon-itt (2018) opined that managers could encourage employees to develop and implement ideas through open communication and by welcoming disagreement with employees. This theme appeared 134 times in the interview transcripts, which represented $47 \%$ of all the codes (Table 4 ). 
Table 4

Frequency of Main Theme Three

\begin{tabular}{lll}
\hline Theme & Number of & Percentage of \\
& Occurrences & Occurrence \\
\hline The Role of the Top Management in Cultivating & 134 & $47 \%$ \\
an Innovative Culture & & \\
\hline
\end{tabular}

Four subthemes appeared under this theme, which were (a) clear goals, (b) corporate culture, (c) risk tolerance and failure tolerance, and (d) employees' ideas. These four subthemes were connected through the innovative corporate culture and the influence of the top management in shaping such an innovative culture. In Table 5, I included the number and percentage of occurrences of the four subthemes.

Table 5

Frequency of Sub-themes under Main Theme Three

\begin{tabular}{lll}
\hline Subtheme & Number of & Percentage of \\
& Occurrences & Occurrence \\
\hline Clear goals & 29 & $22 \%$ \\
Corporate culture & 51 & $38 \%$ \\
Risk and failure tolerance & 15 & $11 \%$ \\
Employees' ideas & 39 & $29 \%$ \\
\hline
\end{tabular}


Nwosu, Osuagwu, Abaenewe, Ndugbu, and Sani (2016) opined that the absence of a clear vision and mission among SME managers and the lack of business focus contribute to the failures of SMEs. Wikhamn et al. (2018) argued that managers could encourage the implementation of the innovation by defining an innovation strategy, communicating the strategy to the employees, and endorsing flexibility. Participant P1C2 stated that you have to put a goal before you start. Participant P1C3 mentioned that having a vision is the most important thing. Shafique and Kalyar (2018) opined that leaders with clear vision could stimulate the employees to innovate and go beyond what is required of them. Participant P1C3 added that the vision should be realistic. Company $\mathrm{C} 1$ had a card that displayed the brand ambition, the brand purpose, and the brand values. Each employee has a copy of this card. Participant P1C4 mentioned that the team is like a sports team where all members support each other towards a common goal. Benbya and Leidner (2018) stressed that leaders should articulate a vision and purpose for innovation to increase the organization ability to innovate. SME managers should make clear strategic decisions about their innovation strategies (Woschke et al., 2017). The clarity of the goals enables all employees to focus their efforts in one direction and achieve progress.

The corporate culture should match and support the strategic goals of the company. Maher (2014) argued that the organizational culture is a major factor which affects the pace of innovation. Furthermore, Naranjo-Valencia et al. (2016) opined that the organizational culture relating to people and behavior can either encourage or hamper innovation. Participant $\mathrm{P} 1 \mathrm{C} 1$ mentioned that their recruitment process assigns high 
weight on the candidate attitude and willingness to adapt to change. Participant P1C2 mentioned that it is important to recruit employees who accept to embrace gradual change. Schiliro (2015) stressed that innovation is about culture and mindset more than anything else. Similarly, Szymańska (2016) argued that organizational culture is the foundation of all the processes within the organization that can play a role in supporting or obstructing innovation. On the other hand, Szymańska (2016) argued that the cultural mismatch is behind the poor level of innovation implementation in SMEs.

Zhai et al. (2018) stressed that SME managers should promote the spirit of innovation and risk tolerance within their firms. Participant P1C1 mentioned that their top management accepted mistakes as long as they learn from them. Participant P1C1 added that they celebrated mistakes. Participants P1C2 and P1C3 mentioned that they accepted mistakes, but they had to understand how to avoid them in the future. Participant P1C4 said that we make mistakes, learn from them, and move on. Padilha and Gomes (2016) argued that managers could reinforce the culture of innovation be demonstrating tolerance for mistakes. Participant P1C1 mentioned that they always talked about new ideas and that their CEO encouraged all the employees to submit their ideas. Participant P1C1 added that they had a monthly competition for ideas. OlmosPeñuela, García-Granero, Castro-Martínez, and D’Este (2017) argued that managers can develop a high innovation culture by encouraging their employees to present their ideas and by tolerating mistakes and failures when such ideas were implemented.

The key role of the top management in cultivating an innovative corporate culture is crucial for the success of innovation implementation. Sattayaraksa and Boon-itt (2018) 
opined that managers could encourage employees to develop and implement ideas through open communication and by welcoming disagreement with employees.

Participant P1C1 mentioned that all ideas were presented and debated. Even ideas coming from the CEO may be rejected or postponed based on open and honest feedback from all employees. Shanker, Bhanugopan, Heijden, and Farrell (2017) opined that top management could encourage their employees to generate more ideas by using a fair and supportive evaluation process for the proposed ideas. Participant P1C4 encouraged diversity by recruiting employees from different countries and with different backgrounds. I checked the LinkedIn profiles of the company C4 and its employees and found that they are 10 employees coming from 7 countries. Benbya and Leidner (2018) argued that managers could foster a culture of innovation by promoting experimentation, diversity, and collaboration.

Szymańska (2016) argued that the corporate culture is a unique feature of each organization that is influenced mostly by the top management. Therefore, the corporate culture is difficult to copy by other companies. Furthermore, a corporate culture that fosters innovation will create value for the company. Valuable resources can give the company a competitive advantage while nontransferable resources can sustain the competitive advantage. Therefore, the importance of the corporate culture in improving the performance is in line with the RBV theory.

\section{Theme 4: Idea Testing, Idea Evaluation, and Seeking Honest Feedback}

Participant P1C1 mentioned that their CEO is always open to discuss ideas with all the employees and that any idea can be discussed and even ideas coming from the 
CEO can be delayed or rejected. Participant P1C2 advised always to take the opinions of others and to take any criticism as a good feedback. Participant P1C2 added that managers should look for people who did not agree with their opinion and try to understand the reasons behind the disagreement. This theme appeared 52 times in the interview transcripts, which represented $18 \%$ of all the codes (Table 6).

Table 6

Frequency of Main Theme Four

\begin{tabular}{lll}
\hline Theme & Number of & Percentage of \\
& Occurrences & Occurrence \\
\hline Idea Testing, Idea Evaluation, and Seeking & 52 & $18 \%$ \\
Honest Feedback & & \\
\hline
\end{tabular}

Nyoni and Bonga (2018) found that one of the reasons behind the high mortality rate among SMEs was the lack of willingness from the SME managers to listen and benefit from criticism. Sattayaraksa and Boon-itt (2018) opined that managers could encourage employees to develop and implement ideas through open communication and welcoming disagreement with employees. Therefore, SME managers should be receptive to differences in opinion and should encourage their employees to provide honest feedback.

Wikhamn et al. (2018) argued that testing new ideas is important especially for the success of innovation. Participant P2C3 said that they always test ideas on a small scale to make sure that it can fly. Participant P1C2 chooses suitable people to try the new 
products and observes them to get instant feedback. Participant P1C3 said that every idea should be tested. Participant P1C3 added that to test new ideas, you go to some of the targeted segment, tell them about the idea, and ask for their feedback without telling them that it is your idea. Heikkilä et al. (2018) opined that any innovation process consists of initiation, ideation, experimentation, and implementation. The experimentation phase consists of continuous design and testing of improvements and innovations (Heikkilä et al., 2018). Likewise, Perry-Smith and Mannucci (2017) argued that the journey of an idea consists of four phases: idea generation, idea elaboration, idea championing, and idea implementation. Idea elaboration is the consistent evaluation of new ideas (PerrySmith \& Mannucci (2017). One of the reasons behind the high mortality rate among SMEs was the lack of willingness from the SME managers to listen and benefit from criticism (Nyoni \& Bonga, 2018). Similarly, Sattayaraksa and Boon-itt (2018) opined that managers could encourage employees to develop and implement ideas through open communication and by welcoming disagreement with employees. Therefore, SME managers should accept criticism for their ideas from their employees and have an open discussion with them.

Hargadon and Sutton (2000) considered ideas and the innovation that comes from ideas as the most valuable resources a firm can have. In addition, De Zubielqui et al. (2014) concluded that ideas could have an impact on the performance of the firms when these ideas are mediated by innovation. The consideration of ideas as valuable resources that can improve the performance of a firm is in line with the RBV theory. Since the ideas that produce innovation are valuable resources, they can provide companies with a 
competitive advantage. Idea testing and evaluation are ways to ensure that the idea is valuable and has potential. Ideas that have a potential for commercialization are valuable resources that align with the RBV theory.

\section{Theme 5: The Customer as a Resource for the Company}

Customers as buyers and users for the products are a key resource for the company. Tobiassen and Pettersen (2018) argued that customers could contribute to the innovation process from start to finish. Furthermore, Wikhamn et al. (2018) argued that SME managers can encourage customers to present their ideas and to participate in the innovation process through continuous communication. Similarly, Tottie, Lager, and Nordqvist (2016) found that companies should maintain a constant communication with their customers to provide the best value for their customers. New and improved products will require collaboration with the customers who will be using these products (Tottlie et al., 2016). This theme appeared 34 times in the interview transcripts, which represented $12 \%$ of all the codes (Table 7 ).

\section{Table 7}

Frequency of Main Theme Five

\begin{tabular}{lll}
\hline Theme & Number of & Percentage of \\
& Occurrences & Occurrence \\
\hline The Customer as a Resource for the Company & 34 & $12 \%$ \\
\hline
\end{tabular}

Tobiassen and Pettersen (2018) found that involving the customers in the innovation process provide a complimentary competency for the company and produce 
solutions that are consistent with the customer needs. Participant P1C1 mentioned that they cared for our customers and they wanted them to be their friends. Participant P1C1 added that the customer experience was always on the mind of the CEO who measured the sales team performance against (three hours, three minutes, three rings): three hours to provide a quotation, three minutes to reply to emails, and three rings to answer the phone. Fidel, Cervera, and Schlesinger (2016) concluded that companies involved in continuous communication with their customers would be in a better position to identify and respond to new market opportunities before their competitors which will create value for their customers and the company as well. Participant P1C3 mentioned that customer needs and pain points represented an invaluable input for innovation. Participant $\mathrm{P} 2 \mathrm{C} 3$ turned to the social media and review sites to get the customer feedback about the company products and the competing products.

A good customer relationship is a win-win relationship between the customer and the company. Ueki (2017) found a significant correlation between customer relationships and product innovation. Abrell, Pihlajamaa, Kanto, Brocke, and Uebernickel (2016) mentioned that customer knowledge includes explicit information about the difficulties with exiting products or services and the requirements for new products or services. Szymańska (2017) opined that both the customers and the companies gain from having direct communications because the customers will fulfill their needs and the companies will guarantee a certain level of sales. Being close to the customer enables the company to improve their current products and plan for future ones. 
A customer can be a valuable resource for the company. Fidel et al. (2016) argued that the customer knowledge is a strategic resource that companies can use to improve innovation. Abrell et al. (2016) mentioned that customer knowledge includes explicit information about the difficulties with exiting products or services and the requirements for new products or services. The company can use the customer knowledge to improve the current position and compete for a better position in the future. Since customers differ from one company to the other and since such customers can provide value to the company, then such customers can be considered valuable and inimitable. Therefore, the customer as a resource aligns with the RBV theory. Furthermore, Fidel, Cervera, and Schlesinger (2016) concluded that companies involved in continuous communication with their customers would be a better position to identify and respond to new market opportunities before their competitors. Such a capability gives the company a sustainable competitive advantage which is aligned with the RBV theory as well.

\section{Applications to Professional Practice}

SME managers can benefit from this study to improve the performance of their firms through the implementation of innovation. Despite the role that SMEs play in the local and global economy, few studies addressed the issue of innovation implementation in SMEs especially in developing countries (Xie et al., 2013). Only 13\% of SMEs in Dubai implement innovation. Such a small percentage means that the potential for improvement in Dubai by implementing innovation in SMEs can be quite considerable. SME managers can increase the competitiveness of their SMEs by incorporating 
innovation into their organizations (Asare, 2014). This study has particular significance because of the lack of studies that address the issue of innovation implementation in SMEs, especially for SMEs in emerging economies. The findings from this study suggest that an innovative culture is a foundation for the successful innovation implementation. SME managers are the key makes of the corporate culture. SME managers should encourage employees to present their ideas, communicate a clear vision and goals for the employees, accept criticism and differences in opinions, and tolerate failure. SME managers should maintain a constant communication with their customers and benefit from the customer knowledge regarding problems with the existing products and needs for new products.

The governmental policies are critical to improving business performance (Obaji \& Olugu, 2014). Thus, the government of Dubai may benefit from this study by addressing key success factors for SMEs through policies and regulations. The regulatory bodies in Dubai like Dubai SME can benefit from this study by providing regulations that can encourage the implementation of innovation in SMEs. In addition, the Dubai Entrepreneurship Academy (DEA), the educational arm of Dubai SME, can benefit from the findings in incorporating the results of this study in their training courses and free workshops. SMEs represent an essential part of the economic growth in developing and developed countries by constituting around $90 \%$ of the total active firms worldwide (Shrirame \& Soni, 2015). In Dubai, SMEs represent 95\% of the business population and contributes around 40\% in Dubai GDP (Dubai SME, 2014). A strong and 
healthy SME sector is vital for the economic development in Dubai; this study can be helpful in promoting economic growth for SMEs and for Dubai economy.

\section{Implications for Social Change}

The results of this study can have implications for social change including job creation, economy protection in downturns, and contribution to economic growth. SMEs have a positive impact on community development through the generation of the employment opportunities (McCann \& Ortega-Argilés, 2016; Qamruzzaman, 2015). Furthermore, SMEs play an essential role in creating employment opportunities and reducing poverty (Ali et al. , 2014). In addition, Çela and Gaspari (2015) stated that SMEs have a positive impact on economic growth, job creation, and social stability. In sum, the results of this study can help in creating a healthy SME section that supports the economic growth, protects the economy in downturns, creates jobs, and contributes to social stability. An increase in the productivity of SMEs means a potential for an increase in Dubai's GDP, an improvement in investment opportunities in Dubai, better working conditions for employees, and possibilities for expanding the operations of Dubai SMEs globally.

\section{Recommendations for Action}

Innovation is a significant element for SME survival and growth (Farsi \& Toghraee, 2014; Kuo \& Chao, 2014). SME managers can increase the competitiveness of their SMEs by incorporating innovation into their organization (Asare, 2014). Furthermore, Hajar (2015) noted that innovation has a positive influence on the 
performance of the company. To adopt innovation, SME managers can follow the following recommendations that resulted from this study: company.

\section{Encourage the Employees to Generate New Ideas}

Ideas are the starting points for innovation. SME managers should encourage their employees to come forth whenever any of them have an idea. SME managers can provide several channels for submitting an idea by the employees like a suggestion box, an email address for ideas, an idea submission system, monthly contests, and periodic meetings. Encouraging employees to present their ideas is a win-win situation where the employees will feel appreciated by their top management, and the management will get free ideas that can improve the company performance.

\section{Create an Innovative Corporate Culture}

The top management is the main influencer on the corporate culture. To promote innovation, SME managers should create a culture that matches their goals. Promoting innovation requires allowing the employees to experiment and try out new things which may succeed or fail. Therefore, SME managers should accept a certain degree of risk and a certain degree of failures.

\section{Formulate and Communicate a Clear Vision and Clear Goals}

The first thing SME managers should do is to formulate a communicate clear vision and goals for all their employees. The clarity of goals encourages employees to work toward these goals. Furthermore, when a group of people focuses on a certain set of clear goals, they will have a better chance to achieve them. 


\section{Evaluate and Test New Ideas}

Ideas are the starting points for innovation. However, not all ideas will reach commercialization. SME managers should seek to evaluate ideas objectively regardless of who submitted the idea. After evaluation, the SME managers should test the ideas before going fully commercial. The purpose of testing is to measure the market need and gauge the customer response. SME managers should find ways for testing that have the minimum financial impact.

\section{Seek Honest Feedback and Accepting Criticism}

As part of idea evaluation, SME managers should seek honest feedback from all those around them. An idea coming from the CEO may get a high evaluation just because it came from the CEO. SME managers should avoid such bias by devising a transparent and objective approach for idea evaluation. One way for achieving transparency and objectivity is to present ideas without mentioning who submitted each idea. SME managers should look for those who differ with them rather than avoid them. Criticism can be a good source of new knowledge.

\section{Seek and Maintain a Constant Communication with the Customers}

Customers and customer knowledge are strategic resources for companies. SME managers should maintain a constant communication with their customers to benefit from these resources. Customers have valuable information about the issues in the current products which SME managers can use to improve these products. SME managers can design future products based on their customers' needs. 
To deliver the findings of this study to the SME managers, I plan to distribute the results of this study to several groups through a number of channels. First, I will provide the five participants with a summary of the findings. Second, I will present a free copy of my dissertation to my company's library. Third, I will consider publishing the findings in academic and business journals. A faster way to reach the SME sector in Dubai, the UAE, and the GCC countries will be to conduct a presentation through one of the SME conferences that take place in Dubai every year such as the SME World Summit. To reach the largest possible audience in Dubai, I will offer Dubai SME and DEA a number of free lectures which will be available for all SME managers and owners.

\section{Recommendations for Further Research}

The purpose of this study was to explore strategies that SMEs managers use to implement innovation to meet performance goals. The findings of this study can help SME managers formulate their strategies to implement innovation in their firms. The population consisted of five SME managers from four SMEs. I did not consider the specific sector or category of the SME when choosing the participants. Future research can target innovation implementation in a specific sector like tourism, manufacturing, trading, IT, real estate, construction, or telecommunications. Such studies that address a particular sector may result in implementation strategies that may be more relevant to that specific sector. Furthermore, such strategies may be more effective for a specific sector than what I identified during this study. Researchers can conduct more targeted research by considering the three business categories within SMEs which are micro, small, and medium. 
Because of the resource limitations, an SME manager may not be able to implement all the findings of this study. Therefore, future quantitative studies can focus on finding the correlation between each of the findings and the improvement in the SME performance. Such a study can identify the actions that can have the highest impact on the company performance. My study and the other recommended studies can be repeated in other areas within the UAE such as Abu Dhabi. Studies can also be conducted throughout the GCC countries which may result in a unified innovation implementation strategy for all SMEs operating in the UAE and its neighbors.

\section{Reflections}

My journey through the DBA doctoral study had many successes as well as setbacks. I learned that such an accomplishment requires dedication, persistence, organization, and time management. Data collection was a very interesting part of the study. I gained new knowledge from the face-to-face discussions with the SME managers which improved my understanding of the innovation implementation strategies in SMEs. The face-to-face meetings required special communications skill and a certain degree of self-confidence. I learned how to articulate my thoughts concisely and accurately through scholarly writing. Despite the knowledge I gained, there were many times where I felt a huge pressure to let go. Today, I feel most proud that I did not give up.

A critical topic when conducting qualitative research through semistructured interviews is the researcher bias. I noticed that bias could creep into the research study in different ways. Data collection through semistructured interviews can introduce a bias 
into the data. To mitigate my personal bias, I had to avoid leading questions. I listened carefully to what each participant wanted to say and later performed a member checking to confirm my analysis and understanding. I kept my emotions and perceptions in check using a reflexive journal.

The DBA study changed the way I viewed the world and influenced my thinking in several ways. First, I learned that for every argument there could be a counterargument. In the social sciences, many things are not black and white. Second, I learned not to take things at face value. I should apply critical thinking before I decide to accept a new information as a fact. I should be open to new findings that may disagree with what I thought was a fact. Third, I learned to be more mindful of my writing which should be clear and concise. Last, I always observed how the Bloom taxonomy manifested through the various phases of my study. While the mere collection of information is important as a starting point, it is the analyses and the synthesis of this information that expands the body of knowledge.

\section{Summary and Study Conclusions}

The purpose of this qualitative multiple case study was to explore strategies that

SME managers use to achieve performance goals. The overarching research question of this study was: What strategies do SME managers use to implement innovation in their organizations to meet performance goals? I interviewed five SME managers from four different SMEs. After analyzing the primary and the secondary data, five themes emerged. 
I concluded that corporate culture that tolerates risk, allows for mistakes, and encourages employees to generate ideas is critical in fostering innovation. The role of the top management is cultivating an innovative corporate culture, recruiting people with the right mindset, and maintain continuous communication with their customers can lead their companies to successful innovation implementation. Finally, ideas are the seeds of innovation and the top management should collect as many ideas as possible, evaluate the ideas objectively, and test the potential ideas before going fully commercial. 


\section{References}

Abrell, T., Pihlajamaa, M., Kanto, L., Brocke, J., \& Uebernickel, F. (2016). The role of users and customers in digital innovation: Insights from B2B manufacturing firms. Information \& Management, 53, 324-335. doi:10.1016/j.im.2015.12.005

Ahmed, S., Halim, H., \& Ahmad, N. (2018). Open and closed innovation and enhanced performance of SME hospitals: A conceptual model. Business Perspective on Research, 6, 1-12. doi:10.1177/2278533717722661

Ajayi, O., \& Morton, S. (2015). Exploring the enablers of organizational and marketing innovation in SMEs: Findings from South-Western Nigeria. SAGE Open, 5(1), 113. doi: $10.1177 / 2158244015571487$

Al-Ansari, Y., Pervan, S., \& Xu, J. (2013). Innovation and business performance of SMEs: The case of Dubai. Education, Business, and Society: Contemporary Middle Eastern Issues, 6, 162-180. doi:10.1108/EBS-04-2013-0012

Ali, S., Rashid, H, \& Khan, M. (2014). The role of small and medium enterprises and poverty in Pakistan: An empirical analysis. Theoretical and Applied Economics, 21(4), 67-80. Retrieved from http://www.ectap.ro/

Ando, H., Cousins, R., \& Young, C. (2014). Achieving saturation in thematic analysis: Development and refinement of a codebook. Comprehensive Psychology, 3(4), 27. doi:10.2466/03.CP.3.4

Antoniadou, V. (2017). Collecting, organizing and analyzing multimodal data sets: The contributions of CAQDAS. In E. Moore \& M. Dooly (Eds), Qualitative 
approaches to research on plurilingual education (pp. 435-450).

doi:10.14705/rpnet.2017.emmd2016.640

Arsel, Z. (2017). Asking questions with reflexive focus: A tutorial on designing and conducting interviews. Journal of Consumer Research, 44, 939-948.

doi:10.1093/jcr/ucx096

Asare, A. (2014). Strengthening innovation performance among SMEs in Tema Metropolitan of Ghana. OIDA International Journal of Sustainable Development, 7(9), 19-28. Retrieved from http://www.oidaijsd.com

Ayyagari, M., Demirguc-Kunt, A., \& Maksimovic, V. (2014). Who creates jobs in developing countries? Small Business Economics, 43, 75-99. doi:10.1007/s11187014-9549-5

Aziati, A., Tasmin, R., Jia, L., \& Abdullah, N. (2014). The relationship of technological innovation capabilities and business innovation capabilities on organization performance: Preliminary findings of Malaysian food processing SMEs. Proceedings of the International ICE Conference on Engineering, Technology and Innovation, 1-8. doi:10.1109/ICE.2014.6871574

Bahrami, N., Soleimani, M., Yaghoobzadeh, A., \& Ranjbar, H. (2016). Researcher as an instrument in qualitative research: Challenges and opportunities. Advances in Nursing \& Midwifery, 25(90), 27-37. doi:10.22037/anm.v25i90.11584

Barney, J. (1991). Firm resources and sustained competitive advantage. Journal of Management, 17, 99-120. doi:10.1177/014920639101700108 
Baumane-Vitolina, I., \& Cals, I. (2013). Theoretical framework for using resource-based view in the analysis of SME innovations. European Scientific Journal: Special Edition, 1, 174-182. Retrieved from http://eujournal.org/

Bayarçelik, E., Taşel, F., \& Apak, S. (2014). A research on determining innovation factors for SMEs. Proceedings of the 10th International Strategic Management Conference, 150, 202-211. doi:10.1016/j.sbspro.2014.09.032

Benbya, H., \& Leidner, D. (2018). How Allianz UK used an idea management platform to harness employee innovation. MIS Quarterly Executive, 17, 139-155. Retrieved from http://www.misqe.org

Berisha, G., \& Pula, J. (2015). Defining small and medium enterprises: A critical review. Academic Journal of Business, Administration, Law and Social Sciences, 1(1), 1728. Retrieved from http://iipccl.org/

Bernard, H. R. (2013). Social research methods: Qualitative and quantitative approaches (2nd ed.). Thousand Oaks, CA: Sage.

Bertoni, F., \& Tykvová, T. (2015). Does governmental venture capital spur invention and innovation? Evidence from young European biotech companies. Research Policy, 44, 925-935. doi:10.1016/j.respol.2015.02.002

Bilbo, D. , Bigelow, B., Escamilla, E., \& Lookwood, C. (2015). Comparison of construction manager at risk and integrated project delivery performance on healthcare projects: A comparative case study. International Journal of Construction Education and Research, 11, 40-53. doi:10.1080/15578771.2013.872734 
Birgit, P., Mike, P., \& Chung-Shing, C. (2018). Needs, drivers and barriers of innovation: The case of an Alpine community-model destination. Tourism Management Perspectives, 25, 53-63. doi:10.1016/j.tmp.2017.11.004

Birt, L., Scott, S., Cavers, D., Campbell, C., \& Walter, F. (2016). Member checking: A tool to enhance trustworthiness or merely a nod to validation? Qualitative Health Research, 26, 1802-1811. doi:10.1177/1049732316654870

Boachie-Mensah, F., \& Acquah, I. (2015). The effect of innovation types on the performance of small and medium-sized enterprises in the Sekondi-Takoradi metropolis. Archives of Business Research, 3(3), 15-46. doi:10.14738/abr.33.1240

Bozkurt, Ö., \& Kalkan, A. (2014). Business strategies of SME's, innovation types and factors influencing their innovation: Burdur model. EGE Academic Review, 14, 189-198. doi:10.21121/eab.2014218050

Burton, C., \& Rycroft-Malone, J. (2014). Resource based view of the firm as a theoretical lens on the organizational consequences of quality improvement. International Journal of Health Policy and Management, 3, 113-115. doi:10.15171/ijhpm.2014.74

Bylok, F., Pabian, A., \& Kuceba, R. (2016). Management of a cluster as a network for cooperation between SMEs in Poland. Small Enterprise Research, 23, 172-181. doi:10.1080/13215906.2016.1221357

Carraresi, L., Mamaqi, X., Albisu, L., \& Banterle, A. (2016). Can strategic capabilities affect performance? Application of RBV to small food businesses. Agribusiness, 32, 416-436. doi:10.1002/agr.21451 
Castillo-Montoya, M. (2016). Preparing for interview research: The interview protocol. The Qualitative Report, 21, 811-831. Retrieved from http://nsuworks.nova.edu/tqr/

Çela, M., \& Gaspari, A. (2015). Small and medium enterprises; Where does Albania stand? European Scientific Journal: Special Edition, 1, 114-126. Retrieved from http://eujournal.org/index.php/esj/index

Cherif, R., Hasanov, F., \& Zhu, M. (Eds.) (2016). Breaking the oil spell: The Gulf falcons' path to diversification. Washington, DC: International Monetary Fund. doi: $10.5089 / 9781513537863.071$

CNR-IRCRES. (2018). The innovation guide for companies in the United Arab Emirates: Towards UAE vision 2021. Retrieved from http://www.economy.gov.ae/english/Media-Section/Pages/Publications.aspx Corbin, J., \& Strauss, A. (2014). Basics of qualitative research: Techniques and procedures for developing grounded theory (4th ed.). Thousand Oaks, CA: Sage.

Cypress, B. (2017). Rigor or reliability and validity in qualitative research: Perspectives, strategies, reconceptualization, and recommendations. Dimensions of Critical Care Nursing, 36, 253-263. doi:10.1097/DCC.0000000000000253

Darawsheh, W. (2014). Reflexivity in research: Promoting rigour, reliability and validity in qualitative research. International Journal of Therapy and Rehabilitation, 21, 560-568. doi:10.12968/ijtr.2014.21.12.560

De Zubielqui, G., Lindsay, N., \& O'Connor, A. (2014). How product, operations, and marketing sources of ideas influence innovation and entrepreneurial performance 
in Australian SMEs. International Journal of Innovation Management, 18(2), 125. doi:10.1142/S1363919614500170

Denzin, N. (1989). The research act: A theoretical introduction to sociological methods (3rd ed.). Englewood Cliffs, NJ: Prentice-Hall.

Denzin, N., \& Lincoln, Y. (2013). Strategies of qualitative inquiry (4th ed.). Thousand Oaks, CA: Sage.

Deshati, E. (2016). Business strategies of SME's, innovation types and factors influencing their innovation: Albanian case. International Journal of Economics \& Management Sciences, 5(2), 1-6. doi:10.4172/2162-6359.1000319

Doody, O., \& Noonan, M. (2016). Nursing research ethics, guidance and application in practice. British Journal of Nursing, 25, 803-807. doi:10.12968/bjon.2016.25.14.803

Drucker, P. (2014). Innovation and entrepreneurship. London, England: Routledge. (Original work published 1985).

Dubai SME. (2014). The state of small \& medium enterprises (SMEs) in Dubai. Retrieved from http://www.sme.ae/StudiesAndResearchDocument/SME_Report_English.pdf El Hussein, M., Jakubec, S., \& Osuji, J. (2015). Assessing the FACTS: A mnemonic for teaching and learning the rapid assessment of rigor in qualitative research studies. The Qualitative Report, 20, 1182-1184. Retrieved from http://www.nova.edu/ssss/QR/QR20/8/el-hussein1.pdf 
Elo, S., Kääriäinen, M., Kanste, O., Pölkki, T., Utriainen, K., \& Kyngäs, H. (2014). Qualitative content analysis: A focus on trustworthiness. SAGE Open, 4(1), 1-10. doi:10.1177/2158244014522633

Eniola, A., \& Ektebang, H. (2014). SME firms performance in Nigeria: Competitive advantage and its impact. International Journal of Research Studies in Management, 3(2), 75-86. doi:10.5861/ijrsm.2014.854

Eniola, A., \& Entebang, H. (2015). SME firm performance-financial innovation and challenges. Procedia - Social and Behavioral Sciences, 195, 334-342. doi:10.1016/j.sbspro.2015.06.361

European Commission (2014). A recovery on the horizon: Annual report on European SMEs 2012/2013. Retrieved from https://ec.europa.eu/docsroom/documents/16149/attachments/1/translations/en/ren ditions/native

Farsi, J., \& Toghraee, M. (2014). Identification the main challenges of small and medium sized enterprises in exploiting of innovative opportunities (Case study: Iran SMEs). Journal of Global Entrepreneurship Research, 4(4), 1-15. doi:10.1186/2251-7316-2-4

Fidel, P., Cervera, A., \& Schlesinger, W. (2016). Customer's role in knowledge management and in the innovation process: Effects on innovation capacity and marketing results. Knowledge Management Research \& Practice, 14, 195-203. doi:10.1057/kmrp.2015.19 
Finfgeld-Connett, D. (2014). Use of content analysis to conduct knowledge-building and theory-generating qualitative systematic reviews. Qualitative Research, 14, 341352. doi:10.1177/1468794113481790

Foghani, S., Mahadi, B., \& Omar, R. (2017). Promoting clusters and networks for small and medium enterprises to economic development in the globalization era. $S A G E$ Open, 7(1), 1-9. doi:10.1177/2158244017697152

Foreman-Peck, J., \& Nicholls, T. (2013). SME takeovers as a contributor to regional productivity gaps. Small Business Economics, 41, 359-378. doi:10.1007/s11187012-9444-X

Freel, M., \& Robson, P. (2017). Appropriation strategies and open innovation in SMEs. International Small Business Journal: Researching Entrepreneurship, 35, 578596. doi:10.1177/0266242616654957

Fusch, P., \& Ness, L. (2015). Are we there yet? Data saturation in qualitative research. The Qualitative Report, 20, 1408-1416. Retrieved from http://nsuworks.nova.edu/tqr/

Genç, N., Özbağ, G., \& Esen, M. (2013). Resource based view and the impacts of marketing and production capabilities on innovation. Journal of Global Strategic Management, 7(2), 24-35. doi:10.20460/JGSM.2013715664

Gibbins, J., Bhatia, R., Forbes, K., \& Reid, C. M. (2014). What do patients with advanced incurable cancer want from the management of their pain? A qualitative study. Palliative Medicine, 28, 71-78. doi:10.1177/0269216313486310 
Grossoehme, D. (2014). Overview of qualitative research. Journal of Health Care Chaplaincy, 20, 109-122. doi:10.1080/08854726.2014.925660

Grzegorz, S., \& Robert, S. (2018). The use of marketing innovations among SMEs. Journal of Fundamental and Applied Sciences, 10(3S), 257-267. doi:10.4314/jfas.v10i3s.21

Guba, E. (1981). Criteria for assessing the trustworthiness of naturalistic inquiries. Educational Communication and Technology Journal, 29, 75-91. Retrieved from http://www.jstor.org/stable/30219811

Hadi, M., \& Closs, J. (2016). Ensuring rigour and trustworthiness of qualitative research in clinical pharmacy. International Journal of Clinical Pharmacy, 38, 641-646. doi:10.1007/s11096-015-0237-6

Hadjimanolis, A. (1999). Barriers to innovation for SMEs in a small less developed country (Cyprus). Technovation, 19, 561-570. doi:10.1016/S01664972(99)00034-6

Hajar, I. (2015). The effect of business strategy on innovation and firm performance in small industrial sector. The International Journal of Engineering and Science, 4(2), 1-9. Retrieved from http://www.theijes.com/

Halim, H., Ahmad, N., Ramayah, Y., \& Hanifah, H. (2014). The growth of innovative performance among SMEs: Leveraging on organisational culture and innovative human capital. Journal of Small Business and Entrepreneurship Development, 2(1), 107-125. Retrieved from http://jsbednet.com 
Halme, M., \& Korpela, M. (2014). Responsible innovation toward sustainable development in small and medium-sized enterprises: A resource perspective. Business Strategy and the Environment, 23, 547-566. doi:10.1002/bse.1801

Hamel, G., \& Prahalad, C. (1990). The core competence of the corporation. Harvard Business Review, 68(3), 79-91. Retrieved from https://hbr.org

Hana, M. (2017). Innovation in the UAE: From first foundations to beyond oil. Global Policy, 8, 414-417. doi:10.1111/1758-5899.12481

Hargadon, A., \& Sutton, R. (2000). Building an innovation factory. Harvard Business Review, 78(3), 157-168. Retrieved from http://hbr.org

Harvey, L. (2015). Beyond member-checking: A dialogic approach to the research interview. International Journal of Research \& Method in Education, 38, 23-38. doi:10.1080/1743727X.2014.914487

Hassan, M., Shaukat, S., Nawaz, M., \& Naz, S. (2013). Effects of innovation types on firm performance: An empirical study on Pakistan's manufacturing Sector. Pakistan Journal of Commerce and Social Sciences, 7, 243-262. Retrieved from http://www.jespk.net

Heikkilä, M., Bouwman, H., \& Heikkilä, J. (2018). From strategic goals to business model innovation paths: An exploratory study. Journal of Small Business and Enterprise Development, 25, 107-128. doi:10.1108/JSBED-03-2017-0097

Hervas-Oliver, J., Ripoll-Sempere, F., \& Moll, C. (2016). Does management innovation pay-off in SMEs? Empirical evidence for Spanish SMEs. Small Business Economics, 47, 507-533. doi:10.1007/s11187-016-9733-x 
Heslina, Payangan, O., Taba, M., \& Pabo, M. (2016). Factors affecting the business performance of the micro, small and medium enterprises in creative economic sector in Makassar, Indonesia. Scientific Research Journal, 4(1), 41-49. doi:10.17727/JMSR.2016/4-012

Hossain, M. (2015). A review of literature on open innovation in small and medium-sized enterprises. Journal of Global Entrepreneurship Research, 5(6), 1-12. doi:10.1186/s40497-015-0022-y

Hossain, M., \& Kauranen, I. (2016). Open innovation in SMEs: A systematic literature review. Journal of Strategy and Management, 9, 58-73. doi:10.1108/JSMA-082014-0072

Houghton, C., Casey, D., Shaw, D., \& Murphy, K. (2013). Rigor in qualitative case-study research. Nurse Researcher, 20(4), 12-17. doi:10.7748/nr2013.03.20.4.12.e326

Houghton, C., Murphy, K, Shaw, D., \& Casey, D. (2015). Qualitative case study data analysis: An example from practice. Nurse Researcher, 22(5), 8-12. doi: $10.7748 / \mathrm{nr} \cdot 22.5 \cdot 8 \cdot \mathrm{e} 1307$

Jitmaneeroj, B. (2016). Reform priorities for corporate sustainability: Environmental, social, governance, or economic performance? Management Decision, 54, 14971521. doi:10.1108/MD-11-2015-0505

Jones, S., \& Hooper, T. (2017). New Zealand's ICT strategy: The respective roles of senior and middle management in promoting collaboration and innovation. Asia \& the Pacific Policy Studies, 4, 484-495. doi:10.1002/app5.199 
Kamalian, A., Rashki, M., Hemmat, Z., \& Jolfaie, S. (2015). Cooperation networks and innovation performance of small and medium-sized enterprises (SMEs). International Journal of Management, Accounting and Economics, 2, 233-242. Retrieved from http://www.ijmae.com/

Karabulut, A. (2015). A research on determining innovation factors for SMEs. Proceedings of the World Conference on Technology, Innovation and Entrepreneurship, 195, 1338-1347. doi:10.1016/j.sbspro.2015.06.314

Katua, N. (2014). The role of SMEs in employment creation and economic growth in selected countries. International Journal of Education and Research, 2(12), 461472. Retrieved from http://www.ijern.com

Kendall, S., \& Halliday, L. (2014). Undertaking ethical qualitative research in public health: Are current ethical processes sufficient? Australian and New Zealand Journal of Public Health, 38, 306-310. doi:10.1111/1753-6405.12250

Kor, Y., Mahoney, J., Siemsen, E., \& Tan, D. (2016). Penrose's the theory of the growth of the firm: An exemplar of engaged scholarship. Production and Operations Management, 25, 1727-1744. doi:10.1111/poms. 12572

Kotey, B., \& Sorensen, A. (2014). Barriers to small business innovation in rural Australia. Australasian Journal of Regional Studies, 20, 405-429. Retrieved from http://anzrsai.org/publications/ajrs/

Kotey, N. (2014). Small business innovation in the hostile environment of Australia's drought stricken rural communities. Australasian Journal of Regional Studies, 20, 325-351. doi:10.5539/ijbm.v12n6p151 
Kuo, D., \& Chao, C. (2014). Exploring the relationships among patterns, information technology, and performance in SME-based service innovation. International Journal of Electronic Business Management, 12(2), 102-111. Retrieved from http://ijebm-ojs.ie.nthu.edu.tw/index.php/IJEBM/index

Lara, F., \& Salas-Vallina, A. (2017). Managerial competencies, innovation and engagement in SMEs: The mediating role of organisational learning. Journal of Business Research, 79, 152-160. doi:10.1016/j.jbusres.2017.06.002

Laursen, K., \& Salter, A. (2014). The paradox of openness: Appropriability, external search and collaboration. Research Policy, 43, 867-876.

doi:10.1016/j.respol.2013.10.004

Leber, M., Bastic, M., \& Buchmeisteri, B. (2014). The trends in usage and barriers of innovation management techniques in new product development. Journal of Mechanical Engineering, 60, 382-388. doi:10.5S45/sv-jme.2013.1611

Lee, R., \& Tang, X. (2018). Does it pay to be innovation and imitation oriented? An examination of the antecedents and consequences of innovation and imitation orientations. Journal of Product Innovation Management, 35, 11-26. doi:10.1111/jpim. 12370

Leedy, P., \& Ormrod, J. (2015). Practical research: Planning and design (11th ed.). Essex, England: Pearson Education.

Leung, L. (2015). Validity, reliability, and generalizability in qualitative research. Journal of Family Medicine and Primary Care, 4, 324-327. doi:10.4103/22494863.161306 
Lewandowska, M. (2014). Innovation barriers and international competitiveness of enterprises from Polish food processing industry: Research results. Oeconomia, 13(4), 103-113. Retrieved from http://acta_oeconomia.sggw.pl/en/

López-Cabarcos, M., Göttling-Oliveira-Monteiro, S., \& Vázquez-Rodríguez, P. (2015). Organizational capabilities and profitability: The mediating role of business strategy. SAGE Open, 5(4), 1-13. doi:10.1177/2158244015616852

Louis, R., \& Balli, F. (2014). Oil price and stock market synchronization in Gulf Cooperation Council countries. Emerging Markets Finance \& Trade, 50, 22-51. doi:10.2753/REE1540-496X500102

Love, J., \& Roper, S. (2015). SME innovation, exporting and growth: A review of existing evidence. International Small Business Journal, 33, 28-48. doi: $10.1177 / 0266242614550190$

Luo, R., \& Chanaron, J. (2017). Innovation capabilities of hi-tech small and mediumsized enterprises (SMEs): A comparative analysis between China and France. Megatrend Review, 14(3), 77-112. doi:10.5937/MegRev1703077L

Mabhungu, I., \& Van der Poll, B. (2017). A review of critical success factors which drives the performance of micro, small, and medium enterprises. International Journal of Business and Management, 12(6), 151-164. doi:10.5539/ijbm.v12n6p151

Maher, L. (2014). Building a culture for innovation: A leadership challenge. World hospitals and health services: The official journal of the International Hospital Federation, 50(1), 4-6. doi:10.4103/2249-4863.161306 
Mamun, A. (2018). Diffusion of innovation among Malaysian manufacturing SMEs. European Journal of Innovation Management, 21, 113-141. doi:10.1108/EJIM02-2017-0017

Manuylenko, V., Mishchenko, A., Bigday, O., Putrenok, Y., \& Savtsova, A. (2015). A comprehensive definition of the concept of innovation in Russian and international science. International Journal of Economics and Financial Issues, 5, 1029-1037. Retrieved from http://www.econjournals.com

Marshall, B., Cardon, P., Poddar, A., \& Fontenot, R. (2013). Does sample size matter in qualitative research? A review of qualitative interviews in IS research. Journal of Computer Information Systems, 54(1), 11-22.

doi:10.1080/08874417.2013.11645667

Marshall, C., \& Rossman, G. (2016). Designing qualitative research (6th ed.). Thousand Oaks, CA: Sage.

Massis, A., Audretsch, D., Uhlaner, L., \& Kammerlander, N. (2018). Innovation with limited resources: Management lessons from the German Mittelstand. Journal of Product Innovation Management, 35, 125-146. doi:10.1111/jpim.12373

McCann, P., \& Ortega-Argilés, R. (2016). Smart specialization, entrepreneurship and SMEs: Issues and challenges for a results-oriented EU regional policy. Small Business Economics, 46, 537-552. doi:10.1007/s11187-016-9707-z

McCusker, K., \& Gunaydin, S. (2015). Research using qualitative, quantitative or mixed methods and choice based on the research. Perfusion, 30, 537-542. doi:10.1177/0267659114559116 
McIntosh, M., \& Morse, J. (2015). Situating and constructing diversity in semistructured interviews. Global Qualitative Nursing Research, 2, 1-12. doi:10.1177/2333393615597674

McKinley, W., Latham, S., \& Braun, M. (2014). Organizational decline and innovation: Turnarounds and downward spirals. Academy of Management Review, 39, 88110. doi:10.5465/amr. 2011.0356

McManamny, T., Sheen, J., Boyd, L., \& Jennings, P. A. (2015). Mixed methods and its application in prehospital research: A systematic review. Journal of Mixed Methods Research, 9, 214-231. doi:10.1177/1558689813520408

Mercandetti, F., Larbig, C., Tuozzo, V., \& Steiner, T. (2017). Innovation by collaboration between startups and SMEs in Switzerland. Technology Innovation Management Review, 7(12), 23-31. doi:10.22215/timreview/1125

Miniaoui, H., \& Schilirò, D. (2017). Innovation and entrepreneurship for the diversification and growth of the Gulf Cooperation Council economies. Business and Management Studies, 3(3), 69-81. doi:10.11114/bms.v3i3.2594

Mitropolitski, S. (2015). Interactive interview: A research note. Forum: Qualitative Social Research, 16(1). doi:10.17169/fqs-16.1.1963

Mizuno, Y. (2014). Collective strategy for implementing innovation in SMEs. Annals of Business Administrative Science, 13, 153-168. doi:10.7880/abas.13.153

Morse, J. (2015). Critical analysis of strategies for determining rigor in qualitative inquiry. Qualitative Health Research, 25, 1212-1222. doi: $10.1177 / 1049732315588501$ 
Moustakas, C. (1994). Phenomenological research methods. Thousand Oaks, CA: Sage. Nada, N., \& Ali, Z. (2015). Service value creation capability model to assess the service innovation capability in SMEs. Proceedings of the 7th Industrial Product-Service Systems Conference, 30, 390-395. doi:10.1016/j.procir.2015.02.218

Naranjo-Valencia, J., Jiménez-Jiménez, D., \& Sanz-Valle, R. (2016). Studying the links between organizational culture, innovation, and performance in Spanish companies. Revista Latinoamericana de Psicología, 48, 30-41. doi:10.1016/j.rlp.2015.09.009

National Commission for the Protection of Human Subjects of Biomedical and Behavioral Research. (1979). The Belmont report: Ethical principles and guidelines for the protection of human subjects of research. Retrieved from http://hhs.gov/ohrp/humansubjects/guidance/belmont.html

Ndesaulwa, P., \& Kikula, J. (2016). The impact of innovation on performance of small and medium enterprises (SMEs) in Tanzania: A review of empirical evidence. Journal of Business and Management Sciences, 4, 1-6. doi:10.12691/jbms-4-1-1

Nitescu, D. (2015). A new beginning for SMEs development? Theoretical and Applied Economics, 22(3), 39-52. Retrieved from http://www.ectap.ro

Noni, I., \& Orsi, L., \& Belussi, F. (2018). The role of collaborative networks in supporting the innovation performances of lagging-behind European regions. Research Policy, 47, 1-13. doi:10.1016/j.respol.2017.09.006

Norek, T. (2014). Efficiency of innovation processes in Polish small and medium-sized enterprises (SMEs). A proposed assessment method and results of empirical 
research. International Journal of Business \& Management Studies, 4(2), 54-60. Retrieved from http://ijmbs.com/42/tomasz-norek.pdf

Nwosu, M., Osuagwu, O., Abaenewe, Z., Ndugbu, M., \& Sani, F. (2016). Small and medium scale enterprises in Nigeria: Challenges and prospects for national economic development. Journal of Business Management and Economics, 4(1), 23-37. doi:10.15520/jbme.2016.vol4.iss01.173.pp23-37

Nyoni, T., \& Bonga, W. (2018) Anatomy of the small \& medium enterprises (SMEs) critical success factors (CSFs) in Zimbabwe: Introducing the 3E model. Journal of Business and Management, 1(2), 1-18. Retrieved from www.dynamicresearchjournals.org

Obaji, N., \& Olugu, M. (2014) The role of government policy in entrepreneurship development. Science Journal of Business and Management, 2, 109-115. doi:10.11648/j.sjbm.20140204.12

Olmos-Peñuela, J., García-Granero, A., Castro-Martínez, E., \& D’Este, P. (2017). Strengthening SMEs' innovation culture through collaborations with public research organizations. Do all firms benefit equally? European Planning Studies, 25, 2001-2020. doi:10.1080/09654313.2017.1279592

Olughor, J., (2015). Effect of innovation on the performance of SMEs organizations in Nigeria. Management, 5, 90-95. doi:10.5923/j.mm.20150503.02

Omerzel, D., \& Jurdana, D. (2016). The influence of intellectual capital on innovativeness and growth in tourism SMEs: Empirical evidence from Slovenia 
and Croatia. Economic Research-Ekonomska Istraživanja, 29(1), 1075-1090. doi:10.1080/1331677X.2016.1211946

Onwuegbuzie, A., \& Byers, V. (2014). An exemplar for combining the collection, analysis, and interpretations of verbal and nonverbal data in qualitative research. International Journal of Education, 6(1), 183-146. doi:10.5296/ije.v6i1.4399

Organization for Economic Cooperation and Development. (2017). Enhancing the contributions of SMEs in a global and digitalized economy. Paris, France: Author. Retrieved from https://www.oecd.org/mcm/documents/C-MIN-2017-8-EN.pdf Organization for Economic Cooperation and Development \& Eurostat. (2005). Oslo manual: Guidelines for collecting and interpreting innovation data (3rd ed.). doi:10.1787/9789264013100-en

Padilha, C., \& Gomes, G. (2016). Innovation culture and performance in innovation of products and processes: A study in companies of textile industry. RAI Revista de Administração e Inovação, 13, 285-294. doi:10.1016/j.rai.2016.09.004

Papetti, A., Marilungo, E., Gregori, F., \& Germani, M. (2016). Driving process innovation: A structured method for improving efficiency in SMEs. Procedia CIRP, 50, 448-453. doi:10.1016/j.procir.2016.04.143

Park, J., \& Park, M. (2016). Qualitative versus quantitative research methods: Discovery or justification. Journal of Marketing Thought, 3(1), 1-7. doi:10.15577/jmt.2016.03.01.1 
Paulet, E., Parnaudeau, M., \& Abdessemed, T. (2014). The SME struggle for financing: A clampdown in European banks post-crisis. Journal of Business Strategy, 35(2), 36-45. doi:10.1108/JBS-09-2013-0089

Penrose, E. T. (1959). The theory of the growth of the firm. New York, NY: John Wiley. Percy, W., Kostere, K., \& Kostere, S. (2015). Generic qualitative research in psychology. The Qualitative Report, 20, 76-85. Retrieved from http://www.nova.edu/ssss/QR/QR20/2/percy5.pdf

Perry-Smith, J., \& Mannucci, P. (2017). From creativity to innovation: The social network drivers of the four phases of the idea journey. Academy of Management Review, 42, 53-79. doi:10.5465/amr.2014.0462

Petkovska, T. (2015). The role and importance of innovation in business of small and medium enterprises. Economic Development, 17(1-2), 55-74. Retrieved from https://www.ceeol.com/search/journal-detail?id=189

Pinget, A., Bocquet, R., \& Mothe, C. (2015). Barriers to environmental innovation in SMEs: Empirical evidence from French firms.M@n@gement, AIMS (Association internationale de management stratégique), 18, 132-155.

doi:10.3917/mana.182.0132

Popa, L., Preda, G., \& Boldea, M. (2010). A theoretical approach of the concept of innovation. Managerial Challenges of the Contemporary Society, 1(1), 151-156. Retrieved from https://econ.ubbcluj.ro/jmccs/

Porter, M. (1996). What is strategy? Harvard Business Review, 74(6), 61-78. Retrieved from https://hbr.org 
Prajogo, D., \& McDermott, C. (2014). Antecedents of service innovation in SMEs: Comparing the effects of external and internal factors. Journal of Small Business Management, 52, 521-540. doi:10.1111/jsbm.12047

Pulka, B., Ramli, A., \& Bakar, M. (2018). Marketing capabilities, resources acquisition capabilities, risk management capabilities, opportunity recognition capabilities and SMEs performance: A proposed framework. Asian Journal of Multidisciplinary Studies, 6(1), 12-22. Retrieved from http://www.ajms.co.in/ Qamruzzaman, Md. (2015). Productivity and performance evaluation of SME sector in Bangladesh: Evidence from the historical data. Journal of Islamic Finance and Business Research, 3, 14-22. Retrieved from http://wbiaus.org/jifbr.html Rahab, R., Anwar, N., \& Priyono, R. (2016). Effect of core competence on sustainable competitive advantages of Batik Banyumas small and medium enterprises. Journal of Comparative International Management, 19(1), 27-45. Retrieved from https://journals.lib.unb.ca/index.php/JCIM

Rexhepi, R. (2014). The impact of innovation in SME's performance. Horizons: International Scientific Journal, 12, 195-206. Retrieved from http://www.uklo.edu.mk

Robinson, O. (2014). Sampling in interview-based qualitative research: A theoretical and practical Guide. Qualitative Research in Psychology, 11, 25-40.

doi:10.1080/14780887.2013.801543

Rogers, E. M. (2003). Diffusion of innovation (5th ed.). New York, NY: Free Press. 
Rua, O., \& França, A. (2017). The linkage between intangible resources and export performance: The mediating effect of innovation. International Journal of Innovation, 5(3), 1-15. doi:10.5585/iji

Sağa, S., Sezena, B., \& Güzela, M. (2016). Factors that motivate or prevent adoption of open innovation by SMEs in developing countries and Policy Suggestions. Proceedings of the 12th International Strategic Management Conference, 235, 756-763. doi:10.1016/j.sbspro.2016.11.077

Salisu, Y., \& Abu Bakar, L. (2018a). Strategic alliance and the performance of SMEs in developing economies: The mediating role of innovation strategy. Asian Journal of Multidisciplinary Studies, 6(2), 47-56. Retrieved from www.ajms.co.in

Salisu, Y., \& Abu Bakar, L. (2018b). Technological collaboration, technological capability, and SMEs product innovation performance. International Journal of Management Research \& Review, 8(2), 1-13. Retrieved from www.ijmrr.com

Sattayaraksa, T., \& Boon-itt, S. (2018). The roles of CEO transformational leadership and organizational factors on product innovation performance. European Journal of Innovation Management, 21, 227-249. doi:10.1108/EJIM-06-2017-0077

Saunila, M. (2016). Performance measurement approach for innovation capability in SMEs. International Journal of Productivity and Performance Management, 65(2), 162-176. doi:10.1108/IJPPM-08-2014-0123

Schiliro, D. (2015). Innovation in small and medium enterprises in the United Arab Emirates. International Journal of Social Science Studies, 3(5), 148-160. doi:10.11114/ijsss.v3i5.1014 
Sehnem, S., Roman, D., Sehnem, A., \& Machado, N. (2016). Competitive advantage in a credit cooperative: The rule of resources. International Business Management, 10, 2768-2779. doi:10.3923/ibm.2016.2768.2779

Shafique, I., \& Kalyar, I. (2018). Linking Transformational leadership, absorptive capacity, and corporate entrepreneurship. Administrative Science, 8(9), 1-17. doi: $10.3390 /$ admsci8020009

Shanker, R., Bhanugopan, R., Heijden, B., \& Farrell, M. (2017). Organizational climate for innovation and organizational performance: The mediating effect of innovative work behavior. Journal of Vocational Behavior, 100, 67-77. doi:10.1016/j.jvb.2017.02.004

Shrirame, A., \& Soni, L. (2015). Examining role of innovation in changing landscape of MSMEs in India. Proceedings of the International Conference on Issues in Emerging Economies (ICIEE), 5(4), 182-188. Retrieved from http://www.abrmr.com/

Simba, A., \& Ojong, N. (2017). Engaged scholarship: Encouraging interactionism in entrepreneurship and small-to-medium enterprise (SME) research. Journal of Small Business and Enterprise Development, 24, 1009-1027. doi:10.1108/JSBED03-2017-0126

Skawińska, E., \& Zalewski, R. (2014). Barriers to the innovation capacity of enterprises in Greater Poland and the expected ways to overcome them. Oeconomia, 13(3), 105-116. Retrieved from http://acta_oeconomia.sggw.pl/en/ 
Sligo, J., Nairn, R., \& McGee, R. (2018). Rethinking integration in mixed methods research using data from different eras: Lessons from a project about teenage vocational behaviour. International Journal of Social Research Methodology, 21, 63-75. doi:10.1080/13645579.2017.1321868

Stanisławski, R., \& Lisowska, R. (2015). The relations between innovation openness (open innovation) and the innovation potential of SMEs. Proceedings of the 2 nd Global Conference on Business, Economics, Management, and Tourism, 23, 1521-1526. doi:10.1016/S2212-5671(15)00330-5

Subhan, Q., Mahmood, T., \& Sattar, A. (2014). Innovation and economic development: A case of small and medium enterprises in Pakistan. Pakistan Economic and Social Review, 52, 159-174. Retrieved from http://pu.edu.pk/home/journal/7/

Susanto, A., \& Wasito, W. (2017). Improve the performance Of SMEs through innovation strategies in developing countries. International Journal of Scientific \& Technology Research, 6(10), 282-285. Retrieved from http://www.ijstr.org/

Sutton, J., \& Austin, Z. (2015). Qualitative research: Data collection, analysis, and management. The Canadian Journal of Hospital Pharmacy, 68, 226-231. doi:10.4212/cjhp.v68i3.1456

Syed, A., Ahmadani, M., Shaikh, N., \& Shaikh, F. (2012). Impact analysis of SMEs sector in economic development of Pakistan: A case of Sindh. Journal of Asian Business Strategy, 2, 44-53. Retrieved from http://www.aessweb.com/journals/5006 
Szymańska, E. (2017). User-driven innovation - The concept and research results. Proceedings of the 7th International Conference on Engineering, Project, and Production Management, 694-700. doi:10.1016/j.proeng.2017.03.182

Szymańska, Y. (2016). Organizational culture as a part in the development of open innovation: The perspective of small and medium-sized enterprises. Management, 20(1), 142-154. doi:10.1515/manment-2015-0030

Talegeta, S. (2014). Innovation and barriers to innovation: Small and medium enterprises in Addis Ababa. Journal of Small Business and Entrepreneurship Development, 2(1), 83-106. Retrieved from http://www.aripd.org/jsbed

Tamayo, J., Romero, J., Gamero, J., \& Martínez-Román, J. (2015). Do innovation and cooperation influence SMEs' competitiveness? Evidence from the Andalusian metal-mechanic sector. Innovar, 25(55), 101-115. doi:10.15446/innovar.v25n55.47226

Teece, D., Pisano, G., \& Shuen, A. (1997). Dynamic capabilities and strategic management. Strategic Management Journal, 18, 509-533. doi:10.1002/(SICI)1097-0266(199708)18:7\%3C509::AID-SMJ882\%3E3.0.CO;2Z

Tehseen, S., Sajilan, S., Adaha, N., \& Abadi, H. (2016). Barriers to retail innovation: Evidence from Malaysian retail SMEs. Australian Academy of Business and Economics Review, 2, 1-21. Retrieved from http:/www.aaber.com.au/ 
Tobiassen, A. \& Pettersen, I. (2018). Exploring open innovation collaboration between SMEs and larger customers: The case of high-technology firms. Baltic Journal of Management, 13, 65-83. doi:10.1108/BJM-01-2017-0018

Tottie, M., Lager, T., \& Nordqvist, S. (2016). From customer understanding to product understanding: Collaboration with industrial lead users in a B2B context. Journal of Business Chemistry, 13(2), 64-79. Retrieved from http://www.businesschemistry.org

Ueki, Y. (2017). The roles of top management characteristics, human resource management and customer relationships in innovations: An exploratory analysis. Asian Journal of Technology Innovation, 25, 206-227. doi:10.1080/19761597.2017.1385962

United States Small Business Administration. (2015). Small business profiles for the states and territories, 2015 [PDF file]. Retrieved from https:/www.sba.gov/sites/default/files/advocacy/SB\%20Profiles\%20201415_0.pdf

Ukpabio, M., Oyebisi, T., \& Siyanbalo, W. (2017). Technological innovation and performance of manufacturing firms in Nigeria. International Journal of Innovative Research and Advanced Studies, 4(11), 10-19. Retrieved from http://www.ijiras.com

Uwajumogu, N., Nwokoye, E., Anochiwa, L., \& Ojike, O. (2015). German Mittelstand: Any lesson for development and sustainability of small and medium scale 
enterprises in Nigeria? Business, Management and Economics Research, 1, 73-78. Retrieved from https://arpgweb.com/

Valaei, N., Rezaei, S., \& Ismail, W. (2017). Examining learning strategies, creativity, and innovation at SMEs using fuzzy set: Qualitative comparative analysis and PLS path modeling. Journal of Business Research, 70, 224-233.

doi:10.1016/j.jbusres.2016.08.016

Varum, C. \& Rocha, V. (2013). Employment of SMEs during crises. Small Business Economics, 40, 9-25. doi:10.1007/s11187-011-9343-6

Wagstaff, C., \& Williams, B. (2014). Specific design features of an interpretative phenomenological analysis study. Nurse Researcher, 21(3), 8-12. doi:10.7748/nr2014.01.21.3.8.e1226

Wang, C., \& Ahmed, P. (2007). Dynamic capabilities: A review and research agenda. International Journal of Management Reviews, 9, 31-51. doi:10.1111/j.14682370.2007.00201.x

Wernerfelt, B. (1984). A resource-based view of the firm. Strategic Management Journal, 5, 171-180. doi:10.1002/smj.4250050207

Wikhamn, W., Armbrecht, J., \& Wikhamn, B. (2018). Innovation in Swedish hotels. International Journal of Contemporary Hospitality Management, 30, 2481-2498. doi:10.1108/IJCHM-06-2017-0323

Wójcik, P. (2015). Exploring links between dynamic capabilities perspective and resource-based view: A literature overview. International Journal of Management and Economics, 45(1), 83-107. doi:10.1515/ijme-2015-0017 
Woods, M., Paulus, T., Atkins, D., \& Macklin, R. (2016). Advancing qualitative research using qualitative data analysis software (QDAS)? Reviewing potential versus practice in published studies using ATLAS.ti and NVivo, 1994-2013. Social Science Computer Review, 34, 597-617. doi:10.1177/0894439315596311

Woschke, T., Haase, H., \& Kratzer, J. (2017). Resource scarcity in SMEs: Effects on incremental and radical innovations. Management Research Review, 40, 195-217. doi:10.1108/MRR-10-2015-0239

Xie, X., Zeng, S., Peng, Y., \& Tam, C. (2013). What affects the innovation performance of small and medium-sized enterprises in China? Innovation: Management, Policy \& Practice, 15, 271-286. doi:10.5172/impp.2013.15.3.271

Yazan, B. (2015). Three approaches to case study methods in education: Yin, Merriam, and Stake. The Qualitative Report, 20,134-152. Retrieved from http://nsuworks.nova.edu/tqr/

Yin, R. (2017). Case study research and applications: Design and methods (6th ed.). Thousand Oaks, CA: Sage.

Yin, R. (2016). Qualitative research from start to finish (2nd ed.). New York, NY: The Guilford Press.

Yu, X., Yan, J., \& Assimakopoulos, D. (2015). Case analysis of imitative innovation in Chinese manufacturing SMEs: Products, features, barriers and competences for transition. International Journal of Information Management, 35, 520-525. doi:10.1016/j.ijinfomgt.2015.03.003 
Zafar, A., \& Mustafa, S. (2017). SMEs and its role in economic and socio-economic development of Pakistan. International Journal of Academic Research in Economics and Management Sciences, 6(4), 1-16. Retrieved from http://www.hrmars.com/journals

Zarei, V., \& Baghban, M. (2014). Innovation implementation to support Iranian SMEs (case study in oil \& gas beneficiary company of Maroon). International Journal of Research in Social Sciences, 4(3), 45-52. Retrieved from http://www.ijsk.org/ijrss

Zhai, Y., Sun, W., Tsai, S., Wang, Z., Zhao, Y., \& Chen, Q. (2018). An empirical study on entrepreneurial orientation, absorptive capacity, and SMEs' innovation performance: A sustainable perspective. Sustainability, 10(2), 1-14. doi:10.3390/su10020314 
Appendix A: Interview Protocol

What I did

Use a starting script:

1. Thank the participant for his/her participation.

2. Introduce myself

3. Introduce the purpose of the interview

4. Remind the participant of his/her right of stopping the interview at anytime without any consequences.

5. Assure the interviewee of confidentiality.

6. Ask for permission to start.

\section{Ask the interview questions:}

7. Start the interview questions.

8. Watch the body language and take notes.

9. Be a good listener and maintain eye contact 10. Ask probing questions like "tell me more about".

\section{Interview Protocol}

What I said (script)

I would like to welcome you and thank you for your participation today. My name is Monther Haddad, and I am a graduate student at Walden University. I am conducting this interview as part of a study in partial fulfillment of the requirements for the degree of DBA. This interview will take around 45 minutes and will include 7 questions about your experience in implementing innovation in SMEs operating in Dubai. I seek your permission to make an audio recording for this interview to be able to accurately document this discussion. Audio recording can be stopped at any time during the interview based on your request.

Allow me to remind you of the following:

1. We can stop the interview at any time. There are no consequences for that.

2. All your responses will remain confidential but will be used to develop a strategy for innovation implementation in SMEs.

3. You have read and signed the consent form.

4. Your participation in completely voluntary and we can stop or take a break at any time.

Please let me know if you have any questions or give the permission to proceed with the interview.

Q1. What strategies are you using to implement innovation?

Q2. What strategy did you find worked best to facilitate innovation implementation?

Q3. What was the impact of innovation in enabling your organization to meet its performance goals? Q4. What resources that your company has that enabled the implementation of innovation?

Q5. How do you see the importance of competencies for the implementation of innovation?

Q6. How did you compete with other companies in the market?

Q7. What additional information would you like to share about innovation implementation strategies in SMEs? 